Artigo

\title{
Patrones de Circulación Atmosféricos-Oceánicos a Meso-Escala Vinculados a las Sequías Severas y Extensas en Venezuela
}

\author{
Franklin J. Paredes Trejo ${ }^{1}$, Humberto Alves Barbosa ${ }^{2}$, Ivis Quiroz Ruiz ${ }^{3}$, \\ Marcos A. Peñaloza-Murillo ${ }^{4}$ \\ ${ }^{1}$ Departamento de Ingeniería Civil, Universidad Ezequiel Zamora, San Carlos, CO, Venezuela. \\ ${ }^{2}$ Instituto de Ciências Atmosféricas, Universidade Federal de Alagoas, Maceió, AL, Brasil. \\ ${ }^{3}$ Departamento de Ingeniería Civil, Universidad Ezequiel Zamora, San Carlos, CO, Venezuela. \\ ${ }^{4}$ Departamento de Física. Facultad de Ciencias, Universidad de Los Andes. Mérida, ME, \\ Venezuela.
}

Recebido: 17/6/2015 - Aceito: 8/1/2016

\begin{abstract}
Resumen
Un grupo de variables oceánicas y atmosféricas en los océanos Pacifico y Atlántico fueron analizadas durante las sequías de gran cobertura (SGC) sobre el territorio venezolano en el periodo 1950-2000. El índice de precipitación estandarizado con agrupación trimestral, se usó como índice de sequías. Las series de precipitación fueron provistas por el Instituto Nacional de Meteorología e Hidrología. Las variables atmosféricas y oceánicas se derivaron de las bases de datos: re-análisis NCEP/NCAR I y ERSSTV3B, respectivamente. Los resultados más relevantes son: (1) las SGC de 4 meses de duración son frecuentes en la temporada de lluvia (junio-septiembre), fuera de ella las SGC persisten hasta 7 meses. Las SPGC $<4$ meses (pulsos seco) suceden en cualquier momento del año; ii) las SGC en la temporada de lluvias coinciden con cambios relevantes en la baja, media y alta tropósfera, en particular con una fuerte actividad convectiva sobre Colombia, La Niña y aguas persistentes frías en el Atlántico Norte; iii) las SGC fuera de la temporada de lluvias coinciden con fuertes y/o persistentes El Niño y aguas persistentemente cálidas en el Atlántico Norte; iv) los pulsos secos son frecuentes durante El Niño y la persistencia de aguas frías en el Atlántico Norte.
\end{abstract}

Palabras clave: sequías, Venezuela, variabilidad climática, teleconexiones.

\section{Meso Scale Oceanic Atmospheric Circulation Patterns Linked with Severe and Extensive Droughts in Venezuela}

\begin{abstract}
Monthly-averaged oceanic and atmospheric variables in the Tropical Atlantic and Pacific Oceans, during the occurrence of extensive droughts in the Venezuelan territory, were studied using the quarterly-timescale Standardized Precipitation Index for the period of 1950-2000. Monthly rainfall time series obtained mainly from the Instituto Nacional de Meteorología e Hidrología were used. The atmospheric set data was extracted from NCEP/NCARs reanalysis I, while the oceanic data set was extracted from the ERSSTV3B product. The most remarkable results were: (1) extensive droughts with a duration of more than 4 months are frequent during the rainy season (June-September), outside this period the extensive droughts can persist until 7 months, whereas the extensive droughts with less than 4 months (dry spells) can occur at any time of the year; (2) extensive droughts throughout the rainy season coincide with significant changes in low, medium and high troposphere such as a strong convective activity over Colombia, La Niña and the presence of colder-than-normal surface temperatures extended across the North Atlantic; (3) extensive droughts outside the rainy season coincide with a stronger El Niño and the presence of warmer-than-normal surface temperatures extended across the North Atlantic; (4) dry spells are more frequent during both El Niño and the presence of colder-than-normal surface temperatures extended across the North Atlantic.
\end{abstract}

Keywords: drought, Venezuela, climate variability, teleconnections.

Autor de correspondência: Franklin J. Paredes Trejo, franklinparedes75@gmail.com. 


\section{Introduccion}

Venezuela, país tropical situado en el extremo norte de Sudamérica (entre $1^{\circ}-12^{\circ} \mathrm{N}$ y $60^{\circ}-73^{\circ} \mathrm{O}$ ), presenta un régimen de lluvia unimodal en gran parte de su territorio continental, con una temporada seca y cálida de diciembre a marzo y, una temporada fría y lluviosa entre junio y septiembre, entre las cuales se da una transición gradual (Vila, 1975; Foghin-Pillin, 2002). Al oeste del meridiano $70^{\circ}$, prevalece un régimen pluviométrico bimodal con un máximo principal entre septiembre y noviembre, y un máximo secundario entre abril y mayo, modulado por una compleja interacción entre la temperatura superficial del mar en las porciones tropicales del océanos Atlántico y Pacifico, la Oscilación del Sur sobre las regiones Niño y la Alta Presión troposférica sobre el océano Atlántico Sur (Pulwarty et al., 1992; Guenni et al., 2008).

La precipitación anual en el territorio venezolano varía desde $400 \mathrm{~mm}$ en la parte noroeste (región del sistema coriano) hasta unos $4000 \mathrm{~mm}$ al sureste (región Guayana) (Martelo, 2003b). Además, algunos gradientes regionales son evidentes, particularmente, en la transición entre los Andes y las planicies centrales (La Cruz et al., 2014). La distribución espacial de la precipitación anual es heterogénea debido en gran medida al factor orográfico, el cual controla el flujo del viento en la baja tropósfera (Torrealba et al., 2010; López et al., 2011). Así, los sistemas montañosos de la costa norte-central; de los Andes (con picos por encima de los $4000 \mathrm{msnm}$ ), en el sur-oeste; y el Escudo Guayanés al sur-este, canalizan este flujo de tal forma, que favorece la ocurrencia del efecto Fohen en algunas de estas regiones (Barry y Seimon, 2000). Esto explica la presencia de franjas áridas en las costas centro-norte, noroeste y noreste, respectivamente.

La temporada seca se inicia con la intrusión del anticiclón subtropical del Atlántico Norte (Paredes et al., 2008; Paredes y Guevara, 2010), el cual produce, gradualmente, una inversión de los alisios en la baja troposfera que, a su vez, inhibe la formación de nubes con gran desarrollo vertical (Riehl, 1954). El inicio y evolución de la estación lluviosa en gran parte del país, depende de la posición latitudinal y actividad de la Zona de Convergencia Intertropical (ZCIT) (Rojas y Alfaro, 2000). Otras situaciones sinópticas son generadoras de lluvias, como por ejemplo: ondas del este, depresiones y tormentas tropicales, vaguadas en altura, entre otras (Riehl, 1954; Gutiérrez et al., 2011), las cuales suelen afectar las subregiones costera norte y noroeste (Lyon, 2003), y la región de Guayana (García, 1998). Estas situaciones, para la costa central, coinciden con el desarrollo de nubosidades asociadas con la advección de polvo africano proveniente del Sahara, principalmente, en julio y agosto (Gutiérrez, 2006).

La precipitación muestra varios modos de variabilidad estacional, anual e interannual, además de una débil variación decadal que se ve reflejada por una difusa alternancia de sucesivas décadas anómalamente secas y húme- das (Martelo, 2003a; Marvez, 2005). A escala regional, la ausencia de lluvias o su ocurrencia deficitaria durante periodos prolongados ha sido bien documentada a lo largo de la historia de Venezuela, tanto lejana (Jiménez, 1924; Humbodlt, 1925; Knoch, 1926; Lecuna, 1939; Röhl, 1948; Vila, 1975; Claxton, 1993; Meggers, 1994, 1996; Johnson, 2005; Williams et al., 2005; Aceituno et al., 2009; Cushman, 2011; Padilla, 2012; Noria, 2013) como reciente (Sánchez, 2005; Mendoza y Puche, 2007; Paredes et al., 2008). Lecuna (1939), por ejemplo, refiere que para 1734, Caracas ya había soportado 20 años de sequía; Vila (1975), por su parte, cita otros ejemplos de sequías prolongadas en siglos recientes.

Estudios previos han sugerido que las condiciones climáticas anómalamente secas en el territorio venezolano se relacionan con complejas teleconexiones oceánicas y atmosféricas originadas en los océanos Pacifico tropical y Atlántico Norte (Behrend, 1987; Rogers, 1988; Martelo, 2003b; Giddings y Soto, 2006; Paredes et al., 2008). En general, los episodios secos suelen ser más intensos y persistentes cuando coinciden con la fase cálida del fenómeno océano-atmosférico denominado El Niño-Oscilación Sur (ENOS) (Cárdenas et al., 2002; Williams et al., 2005; Pierre y Tirado, 2007; Millano et al., 2009; Pérez, 2012; Peñaloza-Murillo, 2014).

La componente oceánica del ENOS evoluciona en el Océano Pacifico tropical, por lo que su estudio suele basarse en el análisis de un grupo de índices derivados de la temperatura superficial del mar (TSM) en cuatro regiones definidas por la comunidad científica internacional y denominadas: i) Región Niño $1+2\left(\mathrm{~N} 1+2 ; 80^{\circ}-90^{\circ} \mathrm{O}, 0^{\circ}-10^{\circ} \mathrm{S}\right)$; ii) Región Niño $3\left(\mathrm{~N} 3 ; 90^{\circ}-150^{\circ} \mathrm{O}, 5^{\circ}-5^{\circ} \mathrm{S}\right)$; iii) Región Niño 4 (N4; $\left.120^{\circ}-170^{\circ} \mathrm{O}, 5^{\circ}-5^{\circ} \mathrm{S}\right)$; y la Región Niño 3.4 (N3.4; $160^{\circ}-150^{\circ} \mathrm{O}, 5^{\circ}-5^{\circ} \mathrm{S}$ ) (Trenbreth, 1997; Guevara, 2008). La TSM en las regiones N3 y N3.4 son las mejores correlacionadas con la precipitación mensual en el territorio venezolano (Martelo, 2003b).

La evidencia observacional sugiere que los episodios más intensos de El Niño modifican temporalmente el patrón normal de circulación del flujo de aire en las celdas de Halley y Walker, respectivamente, (De Souza y Ambrizzi, 2002), y desplaza la ZCIT a una posición más al sur de lo normal, lo que ocasiona un retardo en el retorno de lluvias en amplias regiones de Sudamérica (Hastenrath, 2000; Chaves y Cavalcanti, 2001; Pezzi y Cavalcanti, 2001; Poveda et al., 2001). Análisis más detallados, han encontrado que ENOS puede modular la variabilidad de la TSM del Atlántico Norte a escala interanual, decadal y multidecadal (Pezzi y Cavalcanti, 2001; Kayano et al., 2013). En efecto, la intensidad y extensión de las sequías en el norte y nordeste de Sudamérica parecen depender en gran medida de la fase de ENOS prevaleciente (caliente/fría) y el patrón espacial que configura la TSM tanto en el Atlántico Norte (Poveda y Mesa, 1997; Rojas y Alfaro, 2000; González y Gómez, 2002; Peterson y Haug, 2006; Paredes et al., 2008; 
Kayano y Capistrano, 2014) como en el Caribe (Enfield y Alfaro, 1999).

La influencia de estos patrones oceánicos y de circulación general de la atmósfera en la baja y alta tropósfera sobre las condiciones climáticas prevalecientes a escala local y regional ha sido analizada en Venezuela por Fernández y Fernández (1998), Perdomo (1998), de Bautista et al. (1999), Lozada y Prela (2004), Guevara y Paredes (2007), Millano et al. (2009), Pierre y Tirado (2007), Paredes et al. (2008) y López (2012). Sin embargo, las características espaciales de dichos patrones durante la ocurrencia de episodios secos intensos, persistentes y de gran cobertura espacial sobre el territorio venezolano, así como la naturaleza del acoplamiento de ENOS y la TSA en el Océano Atlántico Norte a lo largo de estos episodios, no han sido investigadas con suficiente detalle.

El propósito de este artículo es doble: i) caracterizar los patrones oceánicos-atmosféricos durante la ocurrencia de episodios secos persistentes y de gran cobertura en el territorio venezolano; y ii) explorar la relación entre la actividad de ENOS, la variabilidad de la TSM en la región oceánica Atlántico Norte y la presencia de episodios secos. Nuestra hipótesis se basa en que gran parte de las sequías pueden ser atribuidas a acoplamientos específicos entre ENOS y la TSM del Atlántico Norte. Cabe destacar que todos los análisis realizados han sido focalizados en la escala estacional y anual debido a la corta longitud de registros pluviométricos disponibles en Venezuela.

La estructura de este trabajo es la siguiente: i) en la sección 2 se describe los materiales usados, además de explicar y justificar los métodos aplicados; ii) en la sección 3 se confronta la hipótesis de trabajo con los resultados derivados de los análisis. Finalmente, se presentan las conclusiones más relevantes.

\section{Materiales y Métodos}

\subsection{Unidad de estudio}

La unidad de estudio hace referencia al área continental del territorio venezolano más la isla de Margarita, esta última situada en el Mar Caribe, al noreste de la línea costera venezolana (limite global: $0.6^{\circ}-12.2^{\circ} \mathrm{N}$ y $59.8^{\circ}$ $\left.73.4^{\circ} \mathrm{O}\right)$.

\subsection{Conjunto de datos}

\subsubsection{Registros pluviométricos}

Dentro de la unidad de estudio se eligieron 349 estaciones de un grupo de 1527 estaciones administradas por el Instituto Nacional de Meteorología e Hidrología (INAMEH) (disponibles en: http://www.inameh.gob.ve/mensual/index.php), el Instituto Nacional de Investigaciones Agropecuarias (INIA) y el Servicio Meteorológico de la Fuerza Aérea Venezolana (SEMETAVIA). Se tomaron en cuenta dos criterios: i) la calidad de los registros (homogeneidad y proporción men- sual de datos faltantes/atípicos), y ii) la cobertura espacial del grupo de estaciones. Las series pluviométricas de las estaciones seleccionadas cubren el periodo 1950-2000, con: i) observaciones mensuales faltantes/atípicas $\leq 30 \%$. Un registro mensual, fuera del rango, media \pm cuatro desviaciones estándar, secuencialmente repetido o englobado, fue tratado como atípico; y ii) homogeneidad mensual, verificada por contraste con una estación cercana de referencia (prueba de homogeneidad normal estándar; $\alpha=0.10$ ) (Guenni et al., 2008)

Para estimar los valores faltantes en las series pluviométricas, se estructuró una matriz $\mathrm{M}$ con las observaciones $\mathrm{a}_{\mathrm{i}, \mathrm{k}}$ disponibles y faltantes, donde i son los meses sucesivos desde enero 1950 hasta diciembre 2000 ( $i=1$...612; equivalente a 51 años x 12 meses/año), mientras que $\mathrm{k}$ son las series pluviométricas asociada cada estación $(\mathrm{k}=1 \ldots 349)$. Un valor faltante en la matriz $\mathrm{M}$, es remplazado por la mediana, calculada al tomar en cuenta los diez meses más similares al mes donde ocurre el registro faltante, usando la distancia euclidiana entre casos estandarizados como métrica de similitud (Torgo, 2003; Teegavarapu, 2014). La matriz resultante se denomina matriz R (dimensión: 612 x $349 \mathrm{y}$ sin datos faltantes).

\subsubsection{Datos oceánicos y atmosféricos}

Del proyecto de re-análisis I del Centro Nacional de Predicción Ambiental de la Administración Nacional Oceánica y Atmosférica de Estados Unidos (NCEP/NCAR, por sus siglas en inglés), se extrajeron para el sector $60^{\circ} \mathrm{S}-$ $60^{\circ} \mathrm{N}, 360^{\circ}-0^{\circ} \mathrm{O}$ y el periodo $1950-2000$, las medias mensuales grilladas de: i) la velocidad vertical (VV) (Pas$\mathrm{cal} / \mathrm{s}$ ) y la humedad especifica (HE) $(\mathrm{g} / \mathrm{kg})$ al nivel $700 \mathrm{Mb}$; la velocidad de las componentes zonal (U) y meridional (V) del viento a los niveles 850 y $200 \mathrm{Mb}(\mathrm{m} / \mathrm{s})$ (resolución espacial: $\left.2.5^{\circ} \times 2.5^{\circ}\right)($ Kalnay et al., 1996) (disponibles en http://www.esrl.noaa.gov/psd/data/gridded/data.ncep.rean alysis.pressure.html); ii) la TSM $\left({ }^{\circ} \mathrm{C}\right.$ (versión ERSSTV3B) (resolución espacial: $2^{\circ} \times 2^{\circ}$ ) (Smith et al., 2008) (disponible en http://www.esrl.noaa.gov/psd/data/gridded/data.noaa.ersst .html); y iii) la presión del aire reducida al nivel del mar $(\mathrm{PNM})$ (milibares) (resolución espacial: $\left.2.5^{\circ} \times 2.5^{\circ}\right)($ Kalnay et al., 1996) (disponible en http://www.esrl.noaa.gov/psd/data/gridded/data.ncep.rean alysis.surface.html).

El módulo de la velocidad del aire (VM) en cada celda fue calculado a partir de sus componentes zonal y meridional, con la siguiente expresión: $\mathrm{VM}=\left(\mathrm{U}^{2}+\mathrm{V}^{2}\right)$. Los niveles troposférico 850, 700 y $200 \mathrm{mb}$ fueron seleccionados para describir adecuadamente las características generales de la atmósfera en la baja, media y alta tropósfera (Kalnay et al., 1996; Randel et al., 2000). El periodo 19502000 se escogió por ser el rango temporal de registros pluviométricos disponibles. 
Las variables TSM, HE y PNM se trasformaron en anomalías mensuales tomando la normal climática estándar 1981-2010 como periodo base (Arguez y Vose, 2011). Así, sí una celda $\mathbf{c}_{\mathrm{x}, \mathrm{y}}$ situada en las coordenadas geográficas: $\mathbf{x}, \mathbf{y}$ $\left(\mathrm{x}=0^{\circ} \ldots 360^{\circ} ; \mathrm{y}=-60^{\circ} \ldots 60^{\circ}\right)$ dentro del arreglo grillado de TSM, HE o PNM, tiene un registro $a_{i, n}$ en el mes $i$ $(\mathrm{i}=1 \ldots 12)$ del año $\mathrm{n}(\mathrm{n}=1950 \ldots 2000)$, la anomalía mensual resulta de restar el valor $\mathbf{a}_{\mathrm{i}, \mathrm{n}} \mathrm{y}$ el promedio de todos los valores a del mes i a lo largo del periodo 1981-2010 (Blunden y Arndt, 2014). Una anomalía positiva (negativa) en el campo TSM, indica la ocurrencia de aguas más cálida (frías) que el promedio observado durante el periodo de la normal climática; de forma similar, se interpretan la HE y la PNM. Las variables VV y VM fueron analizadas considerando sus valores medios mensuales (no sus anomalías), para facilitar su interpretación.

El sector arriba señalado $\left(60^{\circ} \mathrm{S}-60^{\circ} \mathrm{N} / 360^{\circ}-0^{\circ} \mathrm{O}\right)$, se eligió por contener las regiones: Niño (descritas en Guevara, 2008), Atlántico Norte y Atlántico Sur, dentro de las cuales se han encontrado correlaciones estadísticamente significativas entre ciertos índices macro-climáticos (v.g., índice Oscilación del Sur) y la precipitación en el territorio venezolano (Martelo, 2003b; Millano et al., 2009; Paredes y Guevara, 2010).

Los productos distribuidos por el proyecto de reanálisis I del NCEP/NCAR han sido utilizados ampliamente en la caracterización de la circulación atmosférica a gran escala sobre el Trópico (Hastenrath, 2000; Chaves y Cavalcanti, 2001; Poveda et al., 2001; Magaña y Ambrizzi, 2005). La base de datos ERSSTV3B se ha empleado extensivamente en el análisis de los patrones que configura la TSM a escala global (Amador et al., 2006; Hu et al., 2012). En este estudio, ambos conjuntos de datos fueron seleccionados por las características mencionadas y cubrir la totalidad del periodo analizado (1950-2000).

Adicionalmente se emplearon el: i) índice oceánico El Niño (ONI, por sus siglas en inglés y disponible en http://www.esrl.noaa.gov/psd/data/correlation/oni.data); y el ii) índice del Atlántico Norte Tropical (TNA por sus siglas en inglés y disponible en http://www.esrl.noaa.gov/psd/data/correlation/tna.data).

ONI y TNA se usaron para explorar la asociación entre los periodos secos en la unidad de estudio y la TSM promediada espacialmente en las porciones tropicales de los océanos Pacifico y Atlántico.

El ONI es un promedio móvil centrado de la TSM expresada como anomalía (meses: $\mathrm{a}_{\mathrm{i}-1}, \mathrm{a}_{\mathrm{i}} \mathrm{y} \mathrm{a}_{\mathrm{i}+1}$; normal climática 1981-2010), en la región Niño $3.4\left(5^{\circ} \mathrm{N}\right.$ a $5^{\circ} \mathrm{S}$, $\left.120-170^{\circ} \mathrm{O}\right)$. De acuerdo a Trenberth (1997), un evento El Niño (La Niña) ocurre cuando ONI $\geq 0.5{ }^{\circ} \mathrm{C}\left(\leq-0.5^{\circ} \mathrm{C}\right) \mathrm{du}$ rante al menos seis meses consecutivos. Este criterio permitió identificar las fases cálida y fría de ENOS.

La TNA es la anomalía mensual de la TSM (referida a la normal climática 1971-2000), en la región bordeada por el cuadrante $5.5^{\circ}-23.5^{\circ} \mathrm{N}$ y $15^{\circ}-57.5^{\circ} \mathrm{O}$ (en lo sucesivo, región Atlántico Norte). Para identificar la ocurrencia de episodios atípicamente cálidos o fríos en esta región oceánica, se adoptó una variante del enfoque conceptual del ONI. En principio, el primer y tercer cuartil de la serie de tiempo TNA durante el periodo 1950-2000 fueron asumidos como umbrales para la detección de eventos fríos y cálidos $\left(\mathrm{Q}_{1}=-0.20^{\circ} \mathrm{C} ; \mathrm{Q}_{3}=0.20^{\circ} \mathrm{C}\right)$. Luego, una secuencia de valores TNA $\geq 0.20^{\circ} \mathrm{C}\left(\leq-0.20^{\circ} \mathrm{C}\right)$ que persista durante al menos seis meses consecutivos se consideró un episodio con aguas superficiales anómalamente cálidas (frías).

\subsection{Métodos}

\subsubsection{Identificación del trimestre húmedo}

Se calculó la precipitación media anual (PMA) en cada estación durante el periodo 1950-2000. La PMA varía desde 220 a $2670 \mathrm{~mm} /$ año [Fig. 1(a)]. El trimestre más húmedo se estimó empleando el día juliano medio (DJM) como índice de concentración de la lluvia. Walsh y Lawler (1981) detallan el cálculo del DJM. El periodo julio-

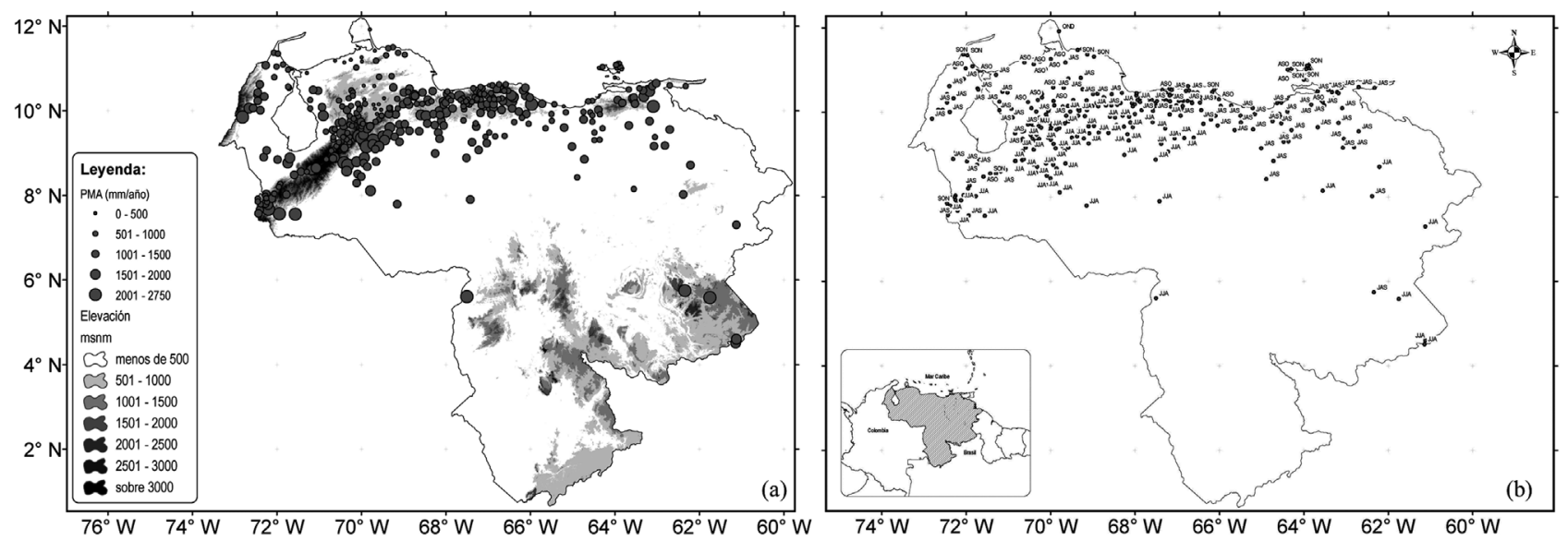

Figura 1 - (a) Elevación media del terreno en la unidad de estudio expresada en metros sobre el nivel del mar (msnm) junto a la precipitación media anual para cada estación (mm por año); (b) Trimestre más húmedo en cada estación. Periodo analizado: 1950-2000. 
agosto-septiembre (44.70\%) y el de junio-julio-agosto (33.24\%) son los trimestres húmedos más frecuentes, indicando que la temporada de lluvia dominante se extiende desde junio hasta septiembre (JJAS). Las zonas con mayor aporte pluvial muestran su trimestre húmedo en JJA (media $=1300 \mathrm{~mm} / \mathrm{año}$ ); el menor aporte pluvial se da en las estaciones con trimestre húmedo en OND (media = $500 \mathrm{~mm} / \mathrm{año)}$ [Fig. 1(b)].

\subsubsection{Estimación de la superficie afectada por condiciones anómalamente secas}

Las series pluviométricas mensuales contenidas en la matriz R se transformaron al Índice de Precipitación Estandarizada (SPI por sus siglas en inglés). El SPI es un índice usado ampliamente para monitorear y analizar sequías meteorológicas, el cual requiere series de precipitación sin datos faltantes a escala mensual (McKee et al., 1993; Mendoza y Puche, 2007; Paredes et al., 2015). El procedimiento consta de cuatro etapas: i) agrupación trimestral móvil; ii) ajuste mensual de cada subserie mensual a una función gamma de dos parámetros (estimados por máxima verosimilitud); iii) cálculo de la probabilidad acumulada de cada elemento, empleando una función gamma incompleta; iv) conversión de cada elemento a un valor normalizado. Este último es el SPI. El procedimiento descrito se aplicó a cada columna de la matriz $\mathrm{R}(\mathrm{k}=1 . . .349)$, resultando una matriz denominada T (dimensión: 612 x 349).

Note que en el cálculo del SPI se empleó una agrupación trimestral, debido a que esta escala temporal permite detectar eventos secos que pueden modificar la humedad del suelo (Guttman, 1998; Heim, 2002; Blain y Brunini, 2005); por tanto, en lo sucesivo las series contenidas en la matriz T, se denominan SPI3. El valor numérico del SPI3 refleja la intensidad de una condición seca en un mes $\mathrm{i}$ $(\mathrm{i}=1 \ldots 12)$ : no seco $(\mathrm{SPI} 3>1.00)$, cerca de lo normal $(1.00 \geq$ SPI3 $>-1.00)$, moderadamente $\operatorname{seco}(-1.00 \geq$ SPI3 $>$ $-1.50)$, severamente seco $(-1.50 \geq \mathrm{SPI} 3>-2.00)$ o extremadamente seco (SPI3 $\leq-2.00)$ (McKee et al., 1993; Mendoza y Puche, 2007).

Cada serie SPI3 contenida en la matriz T se transformó a una serie temporal binaria empleando la siguiente regla de decisión: sí SPI $3_{\mathrm{ijk}} \leq-1.50$, entonces $\mathrm{S}_{\mathrm{ijk}}=1$ (en lo sucesivo, racha seca), de lo contrario, $S_{\mathrm{ijk}}=0$ (racha no-seca), donde i indica los meses $(i=1 \ldots 12)$, $\mathrm{j}$ los años $(\mathrm{j}=1950 \ldots 2000)$ y $\mathrm{k}$ las estaciones $(\mathrm{k}=1 . . .349)$. Una racha seca, según la escala de McKee et al. (1993), coincide con la ocurrencia de un condición extremadamente o severamente seca durante el mes i del año j en el lugar donde se sitúa la estación $\mathrm{k}$.

A escala mensual, la superficie afectada por una racha seca se estimó a partir del porcentaje de estaciones que muestra esta condición. La serie temporal de cobertura seca resultante, se denomina en lo sucesivo: RS1. En este estudio, los eventos secos con una extensión espacial $\geq 10 \%$ du- rante al menos 4 meses consecutivos se denominan: sequías de gran cobertura.

\subsubsection{Estimación del centro seco de una racha seca}

En esta investigación, el centro seco se refiere al lugar donde una racha seca que ocurre en el mes i $(i=1 \ldots 12)$ y año j ( $j=1950 . .2000)$ muestra su mayor intensidad. Para estimar la ubicación del centro seco en el mes $\mathrm{i}$ del año $\mathrm{j}$ sólo se consideran las estaciones $\mathrm{n}$ de $\mathrm{k}(\mathrm{k}=1 \ldots 349)$ que muestran un valor de $\mathrm{SPI} 3_{\mathrm{ijk}} \leq-1.50$, luego las coordenadas del centro seco se calculan por:

Longitud del centro $\operatorname{seco}_{\mathrm{ij}}=\Sigma\left(\mathrm{SPI} 3_{\mathrm{ijk}} \mathrm{x}\right.$ longitud de estación k) / $\Sigma\left(\mathrm{SPI}_{\mathrm{ijk}}\right)$

Latitud del centro $\operatorname{seco}_{\mathrm{ij}}=\Sigma\left(\mathrm{SPI} 3_{\mathrm{ijk}} \mathrm{x}\right.$ latitud de estación $\mathrm{k}) / \Sigma\left(\mathrm{SPI}_{\mathrm{ijk}}\right)$

\subsubsection{Identificación de los patrones que configura el SPI3 en el dominio espacio-tiempo}

La matriz $\mathrm{T}$ resulta compleja de analizar por su gran tamaño (612 meses x 349 estaciones $=213588$ observaciones). Para reducir su dimensión sin perder información relevante sobre la variabilidad espacio-temporal del SPI3, se aplicó un análisis por componentes principales (ACP) en modo $\mathrm{S}$, con rotación ortogonal varimax. El ACP es una técnica multivariante que permite agrupar las variables con base al grado de correlación lineal (columnas en la matriz $\mathrm{T}$ ), en unas pocas variables denominadas Componentes Principales (CP) o Funciones Ortogonales Empíricas (EOFs, por sus siglas en inglés), los cuales retienen una alta proporción de la varianza total presente en la matriz $\mathrm{T}$ (Barnett y Hasselmann, 1979; Wilks, 2011).

La Fig. 2 muestra la varianza porcentual explicada por los primeros CPs identificados por el ACP aplicado a la matriz T. El número de CPs que fue retenido se eligió con base al criterio de Kaiser (Richman et al., 1992), resultando los primeros cuatro componentes principales (CPs), los cuales explican el $43.35 \%$ de la varianza total contenida en la matriz $\mathrm{T}$.

Cada mes de la matriz T (filas; equivalente a 612 meses), está asociado en diferente grado con los cuatro CPs retenidos. La fuerza de esta asociación y su signo se refleja a través de los scores en la matriz de puntuaciones derivada del ACP, la cual es una matriz numérica de tamaño 612 x 4 (meses x 4 CPs). Esta matriz se agregó al vector RS1 (cobertura espacial seca mensual), generando un matriz denominada H de tamaño 612 x 5 [meses x (4 CPs + RS1)].

Para clasificar los meses contenidos en la matriz $\mathrm{H}$ (las filas equivalen a los 612 meses del periodo 1950-2000), según los scores de cada mes en los CPs y la superficie seca observada, se aplicó un análisis de conglomerados (AC) a la matriz $\mathrm{H}$, empleando el algoritmo K-medias (Wilks, 2011). El AC es una técnica multivariante que permite agrupar los casos (filas) de una matriz según su similitud. El criterio de convergencia utilizado en las iteraciones del AC, 


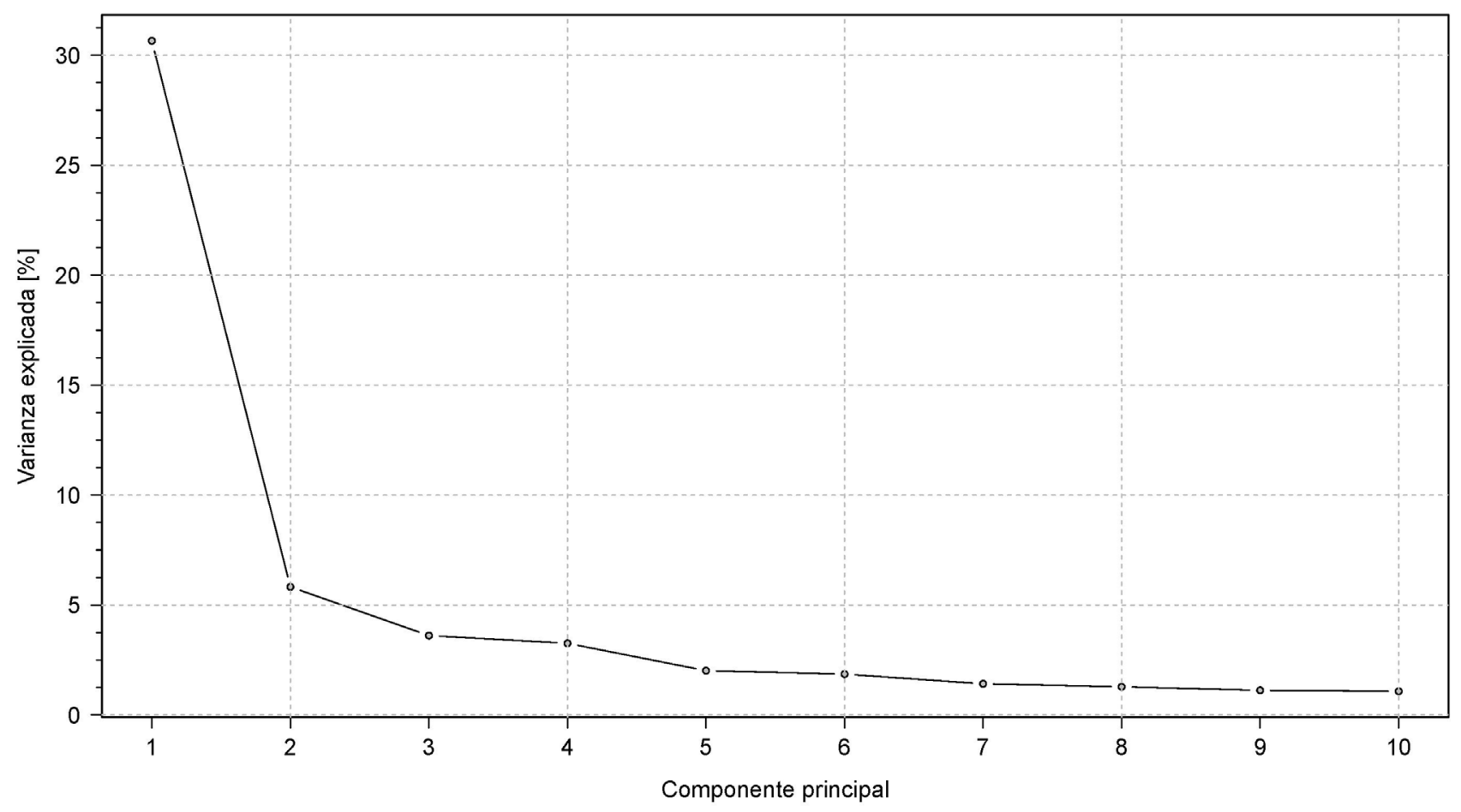

Figura 2 - Varianza explicada por los primeros CPs derivados del ACP aplicado a la matriz T.

fue la ocurrencia simultanea de un mínimo relativo tanto en la suma de cuadrado entre grupos como en el coeficiente de correlación entre los centros de los conglomerados (Chaves y Cavalcanti, 2001). Se evaluaron conglomerados de tamaño 2 hasta 15, encontrándose que la configuración de seis conglomerados conducía a grupos bien diferenciados por la superficie seca observada. La Fig. 3 revela que los meses congregados por $\mathrm{C} 2$ tienen una cobertura seca mayor al $20 \%$, y son marcadamente diferentes al resto de los conglomerados.

Nótese que el número de CPs (cuatro) y conglomerados (seis) no son iguales, debido a que el ACP produce una agrupación espacial (columnas de la matriz T), mientras que el AC conduce a una agregación temporal basada en las puntuaciones de cada mes en los CPs retenidos y la superficie seca observada en la unidad de estudio (filas de la matriz H). Por tanto, los conglomerados pueden ser vistos como un grupo de patrones espaciales que tiende a configurar el SPI3 y que se intercalan a lo largo del tiempo.

\subsubsection{Análisis de la coherencia entre ONI, TNA y la cobertura seca en la unidad de estudio}

Para identificar las periodicidades subyacentes en la cobertura seca mensual en la unidad de estudio durante el periodo 1950-2000, se aplicó una transformada de ondoleta continua (CWT, por sus siglas en inglés) a la serie temporal RS1. El CWT es una técnica de análisis espectral donde una serie de tiempo es descompuesta en los dominios tiempo y escala, usando una versión escalada y trasladada de una función base denominada ondoleta madre. A diferencia del análisis espectral de Fourier, el análisis de ondoletas arroja información simultánea sobre los dominios tiempo y frecuencia de la señal analizada (Vaseghi, 2000; Addison, 2002; Bloomfield, 2004).

El CWT requiere que la serie bajo análisis sea estacionaria (Addison, 2002); por tanto, a cada registro de la serie RS1 se le restó la media (media $=6.36 \%$ ), luego la diferencia resultante fue normalizada por la desviación estándar muestral ( $\mathrm{sd}=7.87 \%)$. Luego, se determinó y restó la tendencia lineal estimada por mínimos cuadrados. El sesgo en el espectro de potencia wavelet (WPS, por sus siglas en inglés), derivado del CWT, se corrigió con la técnica descrita por Liu et al. (2007). El procedimiento computacional para generar el WPS, así como los criterios que sustentan la selección de la ondoleta madre Morlet, se detallan en Torrence y Webster (1999).

A fin de explorar la asociación entre ONI, TNA y la cobertura seca en el dominio tiempo-frecuencia, se aplicó un análisis de coherencia Wavelet (WTC, por sus siglas en inglés) a las series pareadas ONI - cobertura seca y TNA cobertura seca, durante el periodo 1950-2000. La coherencia Wavelet permite identificar bandas de frecuencia donde se relacionan dos series de tiempo, y es definida como el espectro cruzado normalizado por el espectro de potencia individual. Esto da un valor numérico entre 0 y 1; mide la correlación cruzada entre las series contrastadas en función de sus frecuencias (Torrence y Compo, 1998). Previo al análisis, las series mencionadas fueron normalizadas por la desviación estándar de muestreo y luego se les removió la tendencia lineal. 


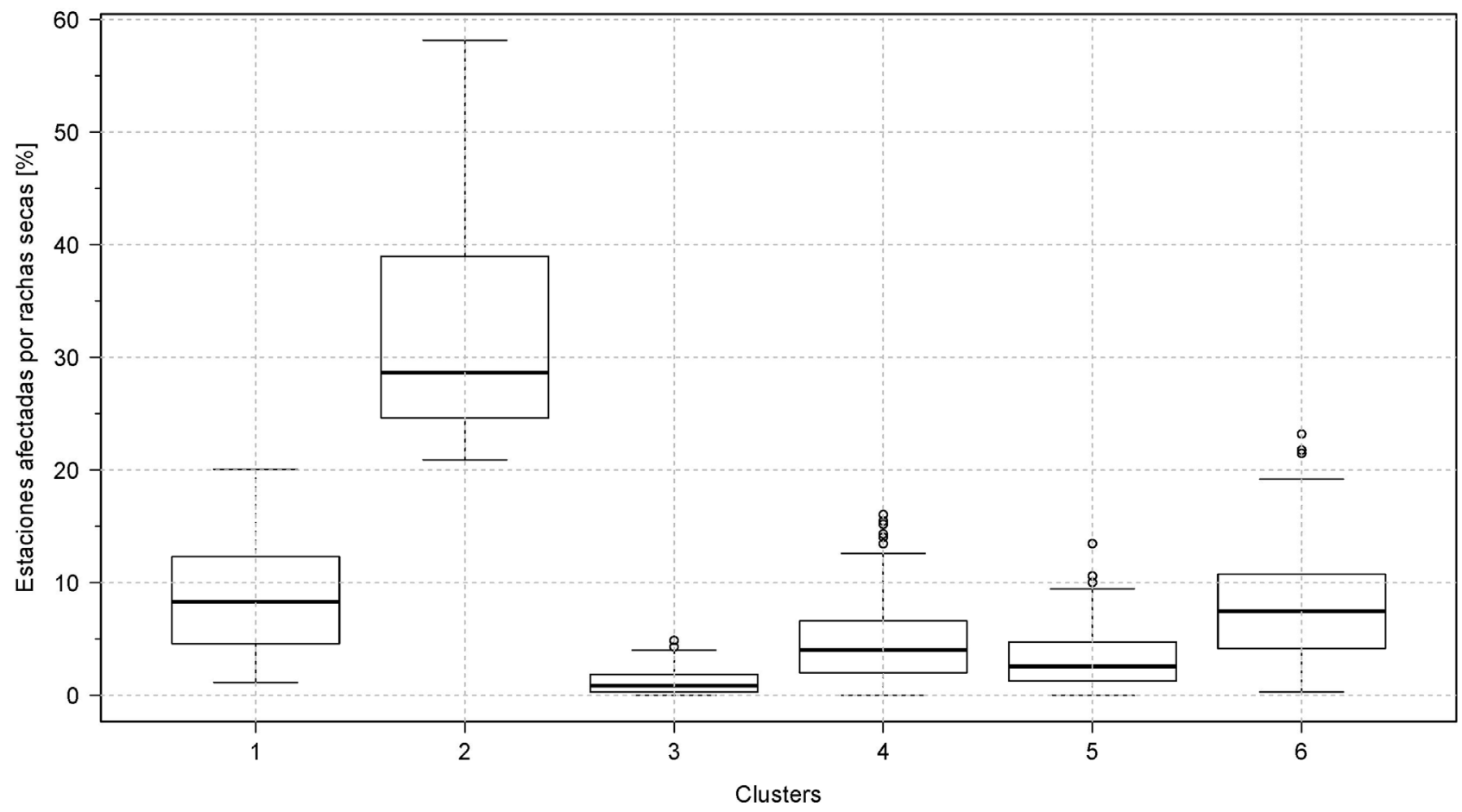

Figura 3 - Cobertura seca mensual de los conglomerados derivados del AC aplicado a la matriz H. El número de miembros desde C1 hasta C6 son: 104, 32, 127, 136, 119 y 92. Con excepción de C1 - C6, los conglomerados son diferentes entre sí, según una comparación múltiple con base en la prueba de Kruskal-Wallis $(\alpha=0.05)$.

\section{Resultados y Discusiones}

\subsection{Características espaciales y temporales de las sequías en el territorio venezolano}

La Fig. 4 muestra el porcentaje de estaciones afectadas por rachas secas en la unidad de estudio durante el periodo 1950-2000, junto a los eventos clasificados como sequías de gran cobertura (cobertura seca $\geq 10 \%$ y duración $\geq 4$ meses). Estos eventos coinciden con los años considerados atípicamente seco por Mendoza y Puche (2007), y Paredes et al. (2008). De los ocho eventos agrupados en esta categoría, E1 y E8 tienen la mayor duración (7 meses). En contraste, E3, E4, E5 y E7 pueden considerarse eventos de corta duración (4 meses). E1 y E8 son similares en el contexto temporal, pues se inician al final de la temporada de lluvia dominante (E1: octubre 1958, E8: septiembre 1997) y finalizan en el siguiente año, previo al comienzo de dicha temporada (E1: abril 1959, E8: marzo 1998). En ambos casos, el pico de cobertura seca ocurre en enero (E1: 42.98\%, E8: 58.17\%).

Una característica que revela la Fig. 4, es que la mayoría de las sequías de gran cobertura de corta duración (i.e., E3, E4, y E7) actúan a lo largo de la temporada de lluvia dominante (junio a septiembre), mientras que los eventos más persistentes en el tiempo, evolucionan fuera de dicha temporada (i.e., E1 y E8). En el caso particular de los eventos E3, E4 y E7, los cuales se desarrollan entre junio y septiembre, presentan su pico de cobertura, en o cerca, de julio (E3: julio 1973, 41.26\%; E4: julio 1975, 14.04\%; E7: junio 1989, 24.07\%).

Una inspección más detallada de la Fig. 4, muestra la ocurrencia de rachas secas de gran cobertura con muy corta duración (en lo sucesivo se denominan, pulso seco); por ejemplo, durante el primer cuatrimestre de 1964, se nota un pulso seco que alcanza su máxima extensión en febrero de este año $(40.69 \%)$ seguido por su rápida contracción. Similarmente, sucede al inicio de 1978.

La Fig. 5 contiene la secuencia temporal de los conglomerados mostrados en la Fig. 3 a lo largo del periodo 1950-2000. El contraste entre las Figs 4 y 5, evidencia que los eventos E1 y E8 (los más persistentes) están relacionados en gran medida con la presencia de $\mathrm{C} 2$ (6 veces en $\mathrm{E} 1$ y 4 veces en E2). A propósito de los eventos E3, E4 y E7, los cuales tienen mayor incidencia durante la temporada de lluvia (junio-septiembre), el conglomerado dominante es $\mathrm{C} 1$ (3 veces en E3, 4 veces en E4 y 3 veces en E7). Mientras que C6 es el más frecuente en los eventos E5, E6 y E8, los cuales se inician al final del periodo de lluvias (agostoseptiembre). Los eventos E1, E2, E3, E4 y E7, comparten en gran medida los mismos conglomerados, sugiriendo que los patrones espaciales que configura el SPI3 durante estos episodios son similares.

$\mathrm{Al}$ explorar la recurrencia temporal de $\mathrm{C} 1, \mathrm{C} 2$ y $\mathrm{C} 6$, entre junio y septiembre (temporada de lluvia dominante), se encuentra un orden de frecuencia de ocurrencia tal que $\mathrm{C} 6>\mathrm{C} 1>\mathrm{C} 2$ (48, 40 y 7 veces, respectivamente). Note que $\mathrm{C} 6$ y $\mathrm{C} 1$ son semejantes en cuanto al rango de cobertura 


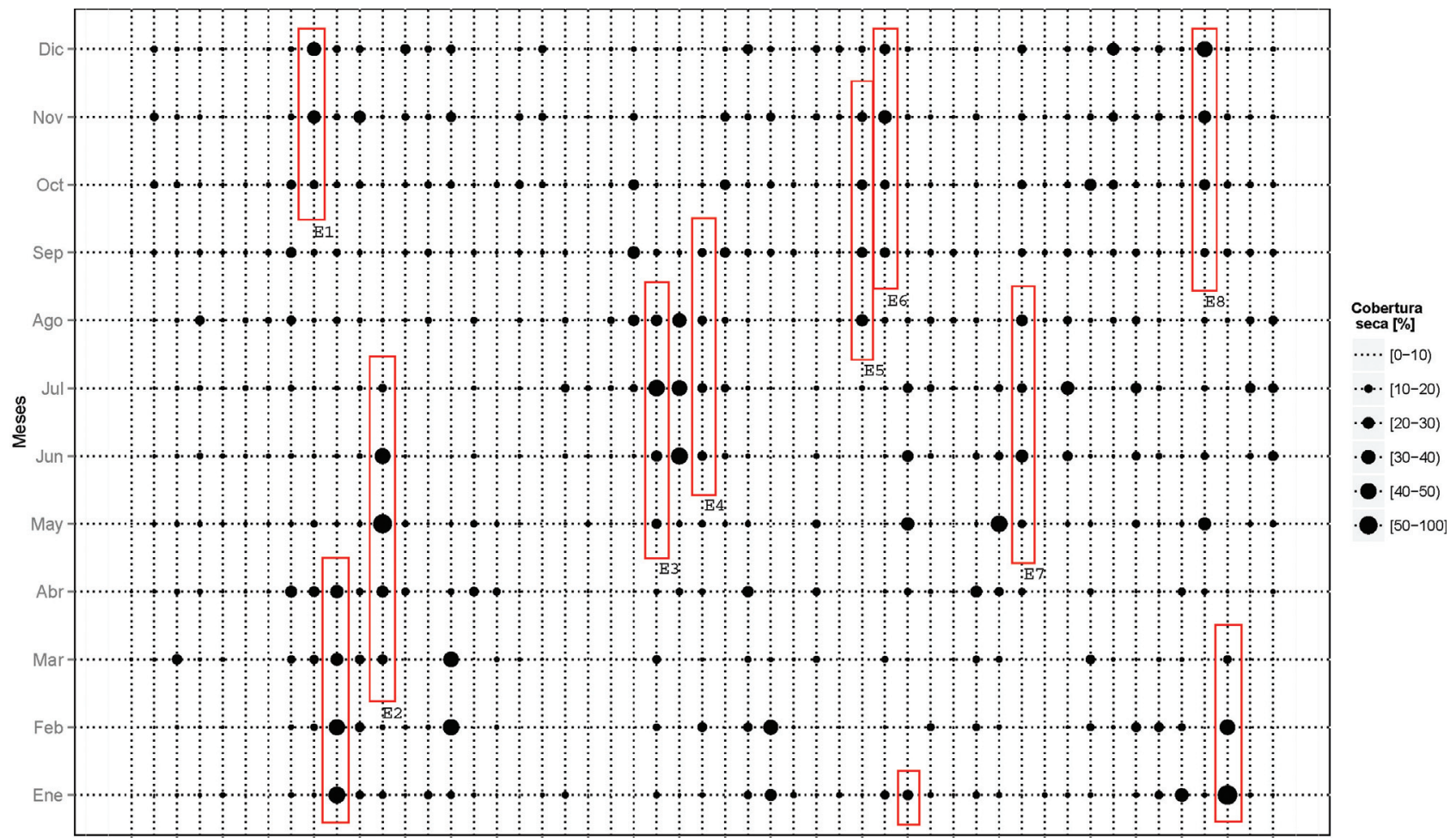

19501952195419561958196019621964196619681970197219741976197819801982198419861988199019921994199619982000 Años

Figura 4 - Cobertura seca mensual en la unidad de estudio durante el periodo 1950-2000. El momento de inicio de las sequías de gran cobertura se indica con las etiquetas E1 hasta E8. Los rectángulos delimitan el lapso donde la cobertura seca es mayor o igual a 10\%.

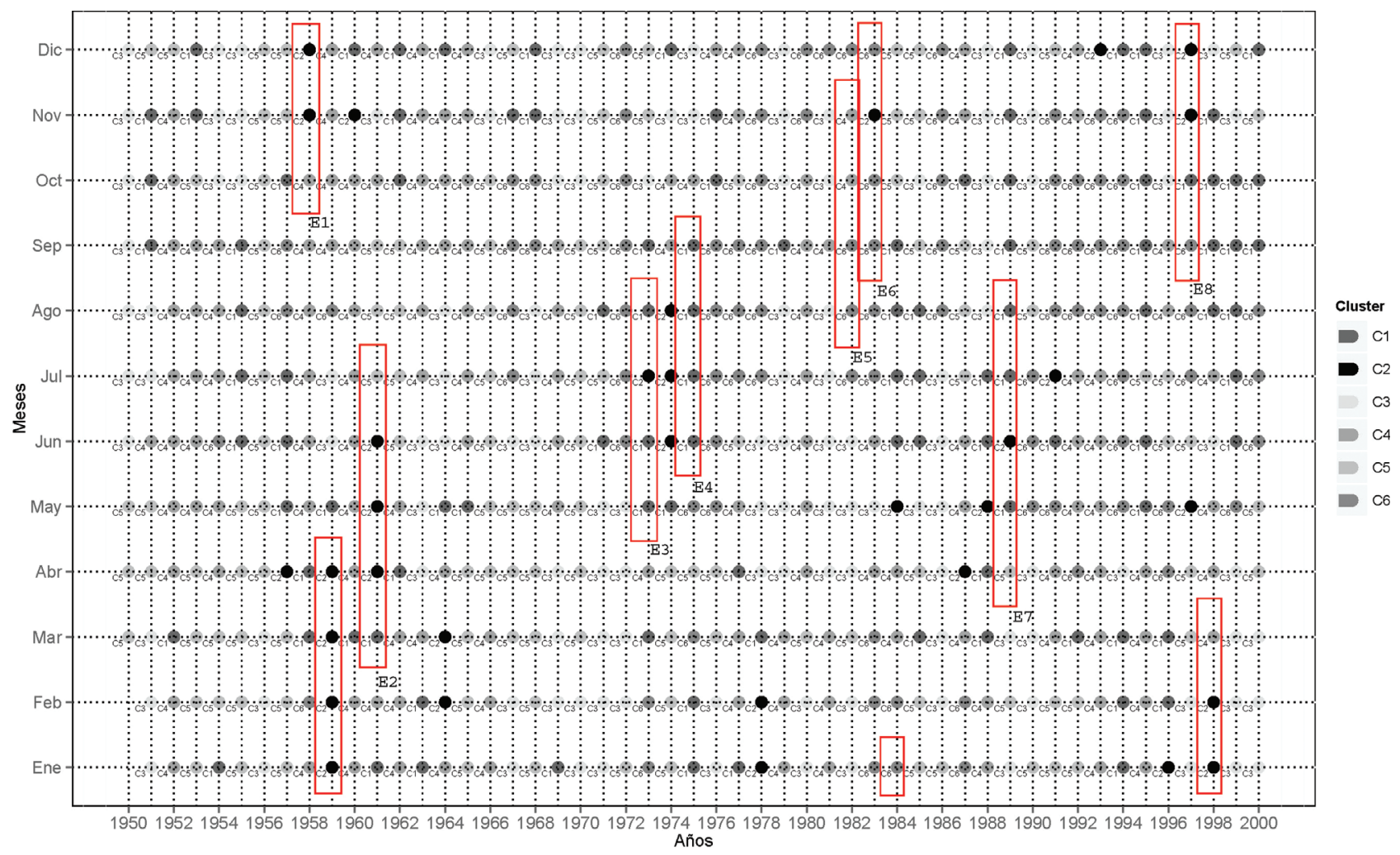

Figura 5 - Secuencia temporal de los conglomerados mostrados en la Fig. 3 durante el periodo 1950-2000. La saturación del color gris se relaciona con la magnitud de la cobertura seca, ordenada en sentido descendente: negro (alta) a gris claro (baja). Las etiquetas E1 hasta E8 y los rectángulos indican lo mismo que en la Fig. 4. 
seca (Fig. 3). En general, estos resultados señalan que durante la estación húmeda (julio-septiembre): i) $\mathrm{C} 2$ es poco frecuente y suele estar vinculado a eventos secos de corta duración (pulso seco); ii) C6 es el patrón más frecuente, pero raras veces está asociado a sequías de gran cobertura; y iii) $\mathrm{C} 1$ es el patrón más común durante el desarrollo de sequías de gran cobertura.

La distribución espacial del SPI3 en la unidad de estudio durante la ocurrencia de $\mathrm{C} 1$ hasta $\mathrm{C} 6$, a lo largo de la temporada de lluvia dominante (junio-septiembre), se muestra en la Fig. 6. C1 y C6 tienden a configurar patrones nucleados; esto significa, subregiones aisladas con condiciones secas más intensas que sus alrededores. En el caso particular de C1, la mayor sequedad, promediada a nivel de las estaciones, se evidencia en los estados Sucre y Nueva Esparta (noreste costero), el arco geográfico formado por los estados Carabobo, Cojedes, Yaracuy, Portuguesa, Trujillo y la costa este del Lago de Maracaibo (noroeste de Venezuela), y la Alta Guajira en el estado Zulia (extremo noroeste de Venezuela).

La localización del centro seco durante la evolución de los eventos E1 a E8 se muestra en la Fig. 7. En todos ellos, el centro seco describe una trayectoria irregular dentro de una estrecha región limitada por $69.35^{\circ}-67.02^{\circ} \mathrm{O}$ y $9.31^{\circ}-10.04^{\circ} \mathrm{N}$. Este resultado revela la presencia de un corredor geográfico donde las sequías de gran cobertura alcanzan su mayor intensidad a lo largo del tiempo, independientemente de que éstas ocurran dentro o fuera del periodo de lluvias. En consecuencia, esta subregión del centro-oeste venezolano es la más propensa a condiciones anómalamente seca durante el periodo analizado. En este punto, cabe destacar que el referido corredor seco no se refleja en la Fig. 6, debido a que estos mapas se derivan del promedio del SPI3 durante la temporada de lluvia dominante y ocurrencia de los conglomerados $\mathrm{C} 1$ a $\mathrm{C} 6$; por tanto, los eventos E1 a E8, los pulsos seco, así como los eventos no seco están mezclados.

En general, los resultados descritos muestran que: i) las sequías de gran cobertura pueden ocurrir dentro o fuera de la temporada de lluvia dominante (junio-septiembre); ii) el patrón espacial que configura el SPI3 en la unidad de estudio, es moderadamente similar durante la evolución de las sequías de gran cobertura, en particular cuando suceden durante la temporada de lluvias; iii) cuando se manifiestan sequías de gran cobertura, la sub-región centro-oeste de la unidad de estudio es la más propensa a sufrir condiciones secas severas; iv) las sequías de gran cobertura no afectan la zona sur de la unidad de estudio (latitud $\leq 8^{\circ}$ ), de hecho, en esta región solo se identificó un pulso seco a inicios de 1970 (centro seco: $64.54^{\circ} \mathrm{O}, 6.59^{\circ} \mathrm{N}$ ).

Las sequías de gran cobertura que causan mayores impactos sobre los sectores agrícola e hidroeléctrico son aquellas que suceden durante la temporada de lluvias (Paredes et al., 2014). Por tanto, en la próxima sección se exploran las condiciones oceánicas y atmosféricas prevalecientes cuando sucedieron los eventos E3, E4 y E7.

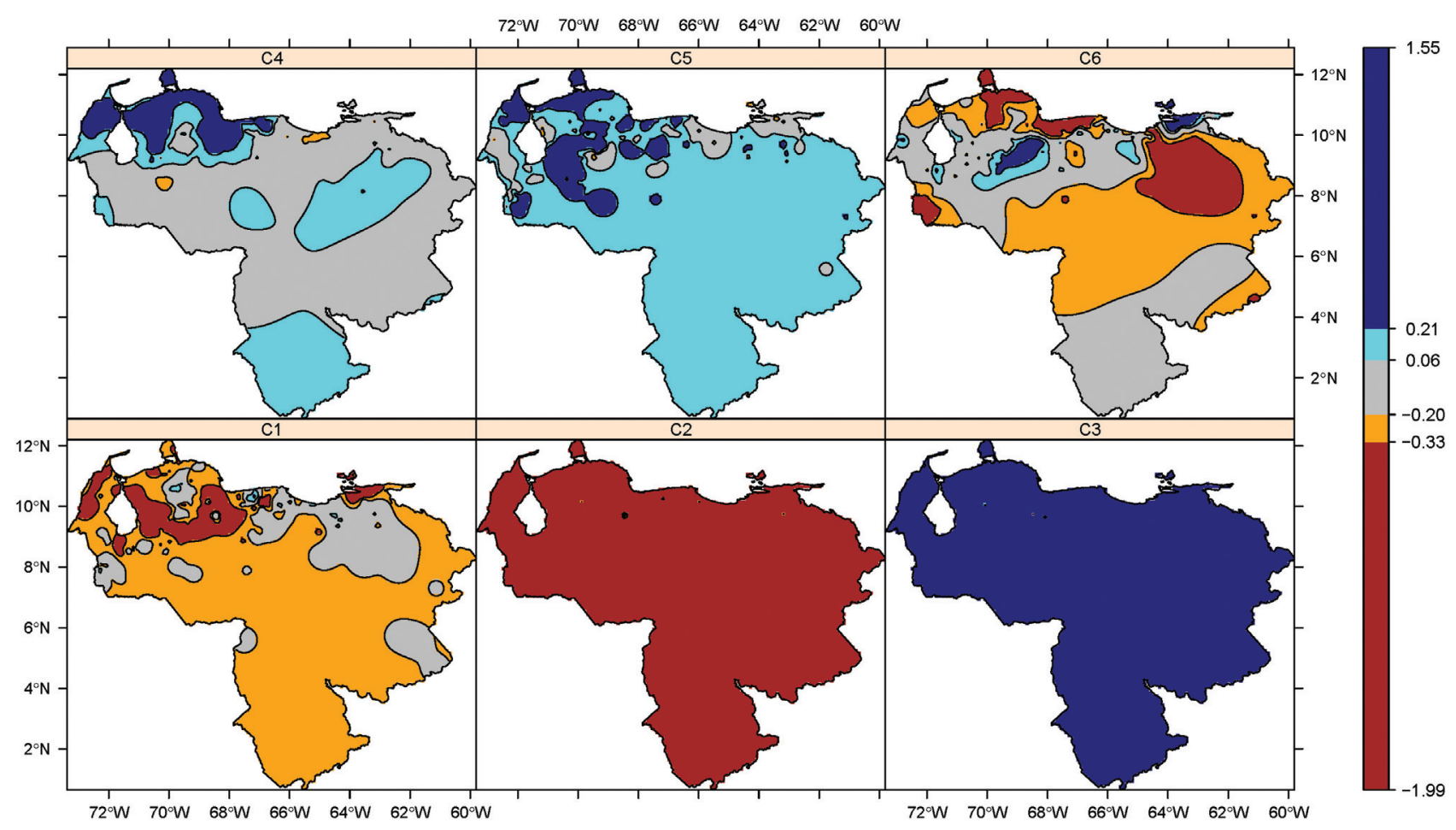

Figura 6 - Distribución espacial del SPI3 sobre la unidad de estudio durante la presencia de los conglomerados C1 hasta C6 entre junio y septiembre del periodo 1950-2000. En cada mapa, los valores del SPI3 se promedian por estación durante la ocurrencia del conglomerado; luego se aplica una interpolación basada en el método kriging empleando un variograma ajustado. 


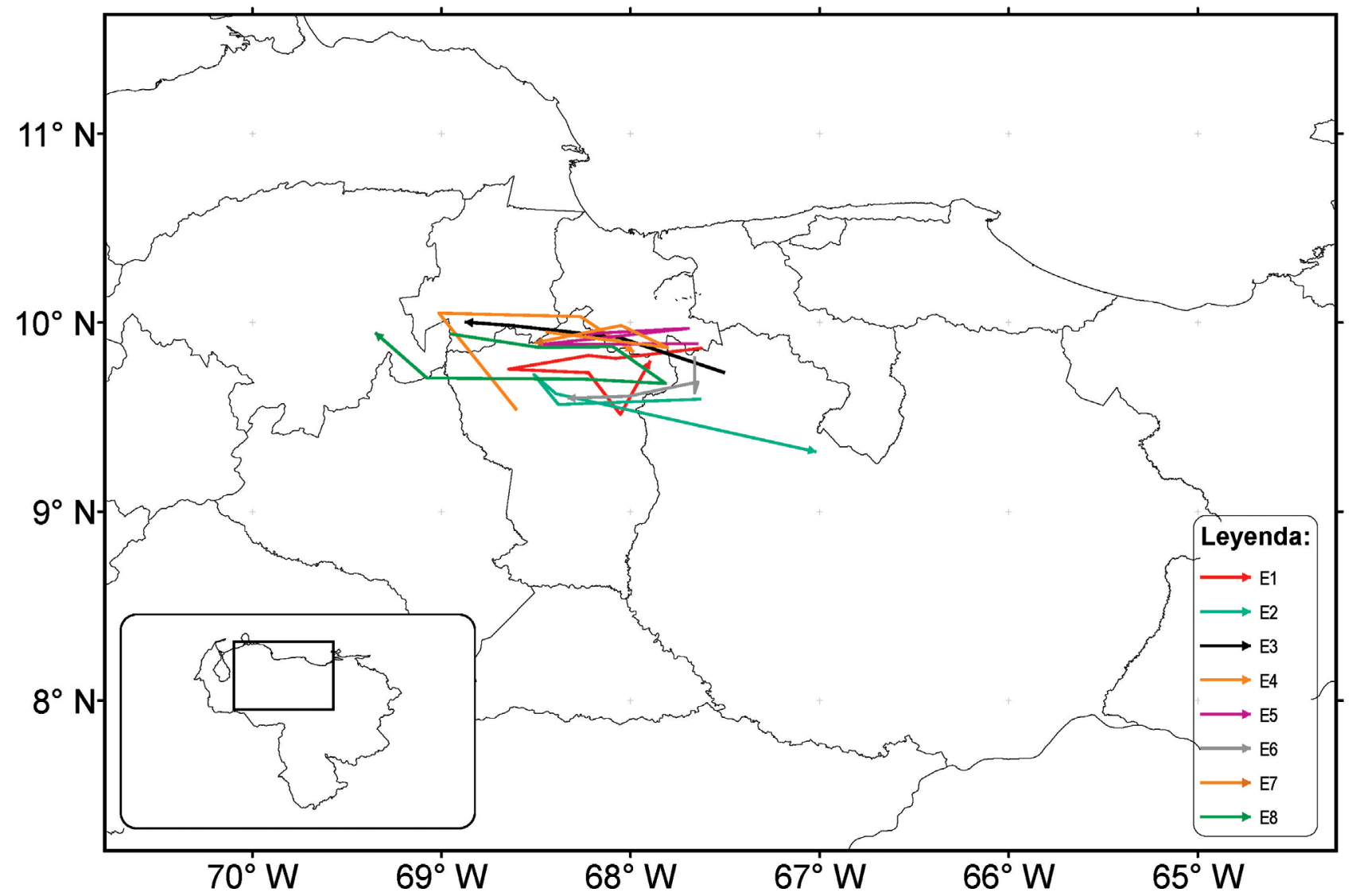

Figura 7 - Trayectoria del centro seco durante las sequías de gran cobertura mostradas en la Fig. 4. La punta de la flecha indica el sentido de avance del centro seco.

\subsection{Condiciones oceánicas y atmosféricas prevalecientes durante las sequías de gran cobertura (temporada de lluvia)}

Al examinar la asociación entre los índices ONI y TNA promediados anualmente durante la temporada de lluvia dominante (junio-septiembre) en el periodo 19502000 se evidencia una correlación positiva y estadísticamente no significativa entre la TSM en las regiones oceánicas Niño N3.4 y Atlántico Norte $(\mathrm{r}=0.119 ; \alpha=0.05$; $\mathrm{n}=51$ años). Cuando se desfasa un año el índice ONI con respecto al índice TNA, la correlación resulta estadísticamente significativa ( $\mathrm{r}=0.321 ; \alpha=0.05 ; \mathrm{n}=50$ años). Este resultado muestra que la variación interanual de la TSM en estas regiones para el cuatrimestre junio-septiembre no está linealmente acoplada, sin embargo la persistencia de aguas anómalamente cálidas (frías) en la región Niño N3.4. en el año previo analizado, favorece la ocurrencia de aguas anómalamente cálidas (frías) en la región Atlántico Norte. La modulación parcial observada de la TSM en el Océano Atlántico por parte de la TSM en la región Niño N3.4 es consistente con Chiang y Vimont (2004) y Dong et al. (2006).

La Fig. 8 muestra la TSM promediada a escala global durante la presencia de E3, E4 y E7 sobre la unidad de estudio. La TSM en el Océano Pacifico tropical es similar en estos eventos; en particular, dentro de la región Niño N3.4 $\left(160^{\circ}-150^{\circ} \mathrm{O}, 5^{\circ}-5^{\circ} \mathrm{S}\right)$. Note que el evento E3 [Fig. 8(a)], tiene una estructura dipolar en el Océano Atlántico aunque, la TSM en sus núcleos no es estadísticamente diferente a la TSM media de largo plazo (1981-2010). En general, el contraste visual de los patrones oceánicos asociados a los eventos E3, E4 y E7 sugiere que las sequías de gran cobertura durante la temporada de lluvia podrían estar asociadas a un enfriamiento de las aguas superficiales del Océano Pacifico tropical flanqueado con aguas cálidas alrededor de $40^{\circ} \mathrm{Ny} 40^{\circ} \mathrm{S}$, sin anomalías de importancia en la TSM del Océano Atlántico. Para explorar las condiciones atmosféricas prevalecientes, el evento E4 se asume representativo del grupo de eventos E3, E4 y E5. Esta escogencia se basa en el hecho de que E4 se desarrolla dentro del periodo de lluvias dominante (junio-septiembre) (ver Fig. 4).

Los valores promedios de la PNM, HE y VV durante el evento E4 se muestran en la Fig. 9. La PNM sobre el territorio venezolano es cercana al promedio de largo plazo entre junio y septiembre (meses en que actúa E4). Sobre el Océano Atlántico tropical, una franja con anomalías negativas en la PNM y estadísticamente significativas, se extiende desde el noroeste de África hasta costa afuera del 


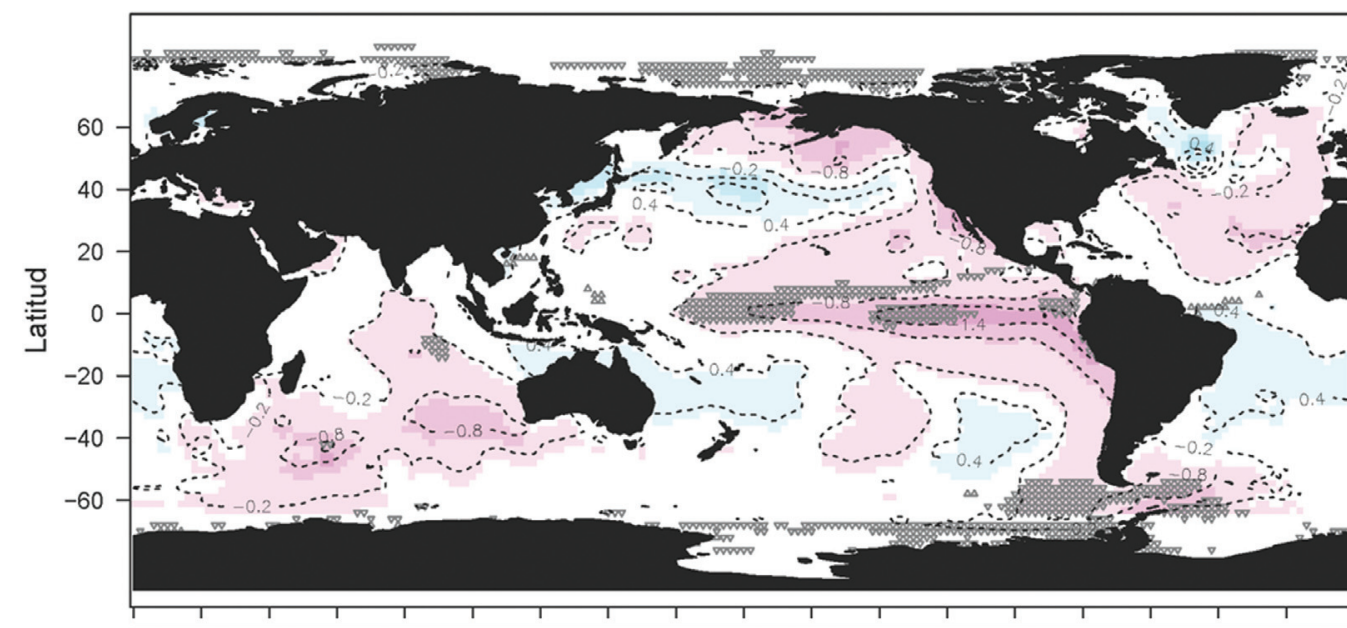

(a)
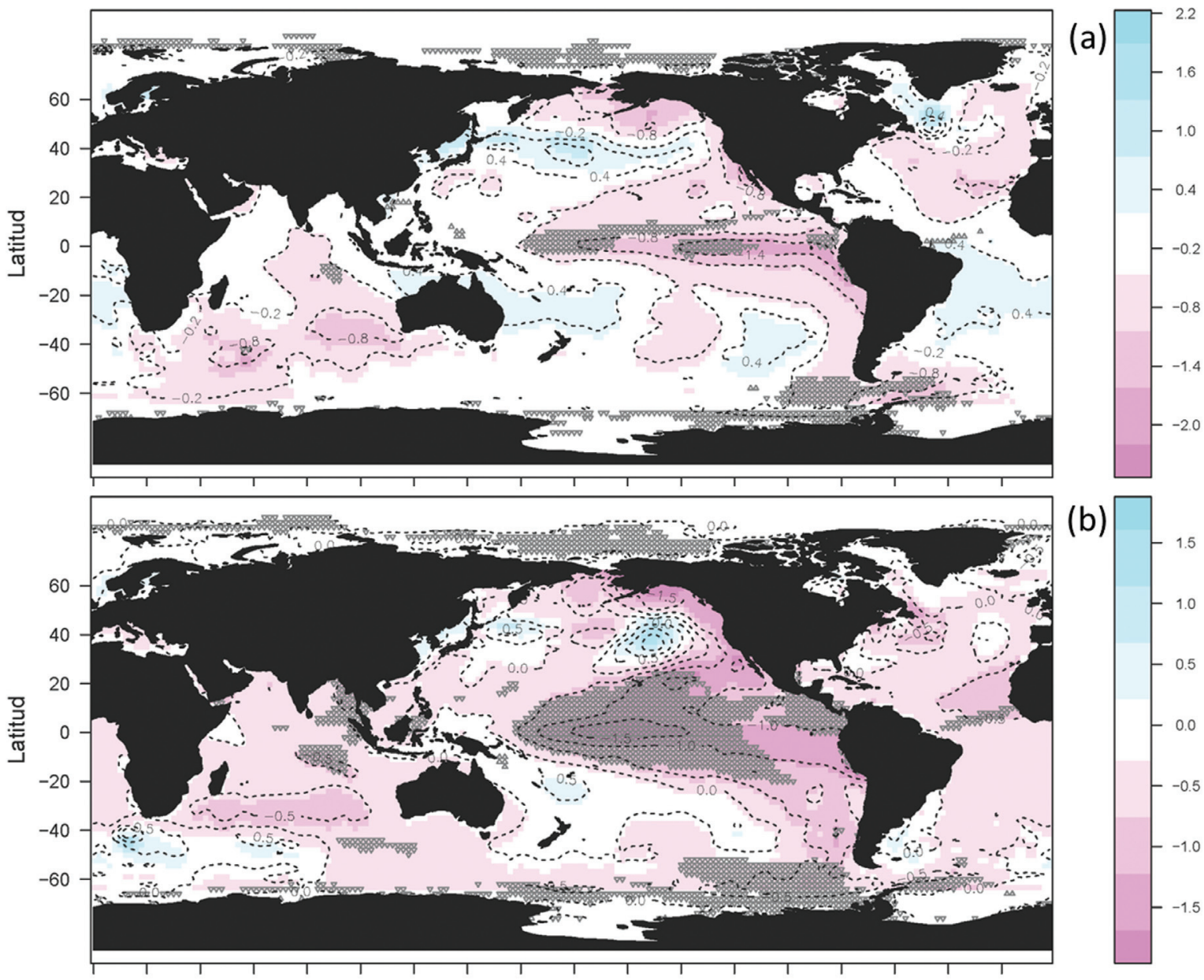

(b)
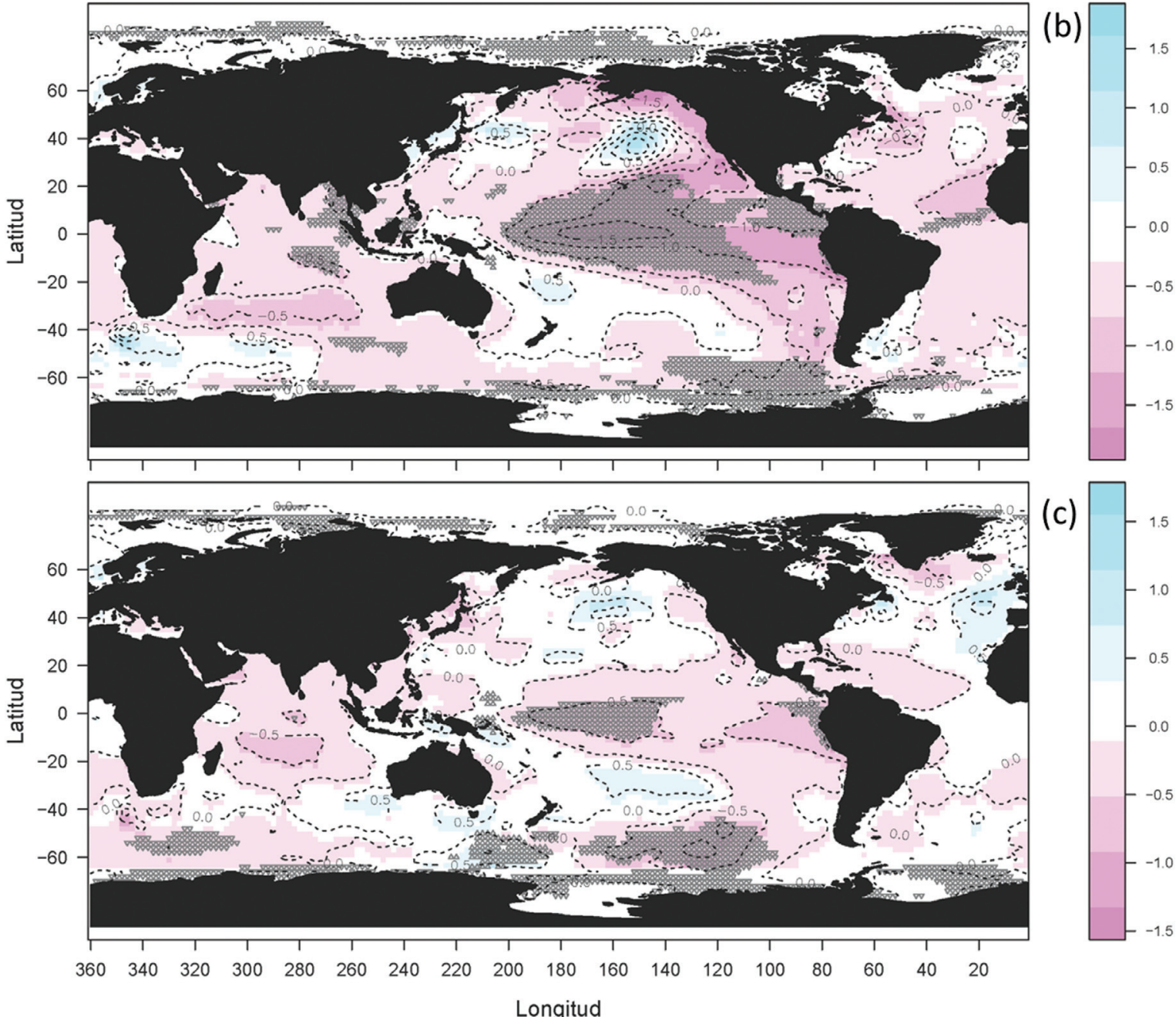

(c)

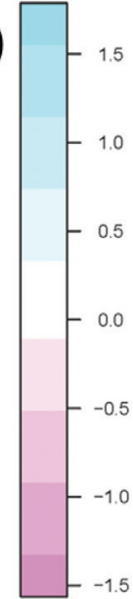

Figura 8 - TSM promedio expresada en grados Celsius durante la ocurrencia de los eventos: (a) E3, (b) E4 y (c) E7 mostrados en la Fig. 4. Los triángulos orientados hacia arriba (abajo) indican que la TSM media es mayor (menor) a la media de largo plazo (1981-2010), con base en una prueba t de Student $(\alpha=0.05)$.

nordeste de Brasil (NEB) [Fig. 9(a)]. En el Océano Pacifico tropical central, se manifiestan dos amplios núcleos con valores de PNM anómalamente altos y moderadamente alineados con $20^{\circ} \mathrm{N}$ y $20^{\circ} \mathrm{S}$ [Fig. 9(a)]. En un contexto espacial, estos núcleos se sitúan sobre una masa de aguas frías en esta región [Fig. 8(b)].

A $700 \mathrm{mb}$ (altitud: $\sim 3 \mathrm{~km}$ ), se evidencia un déficit de humedad específica sobre el territorio venezolano que se 


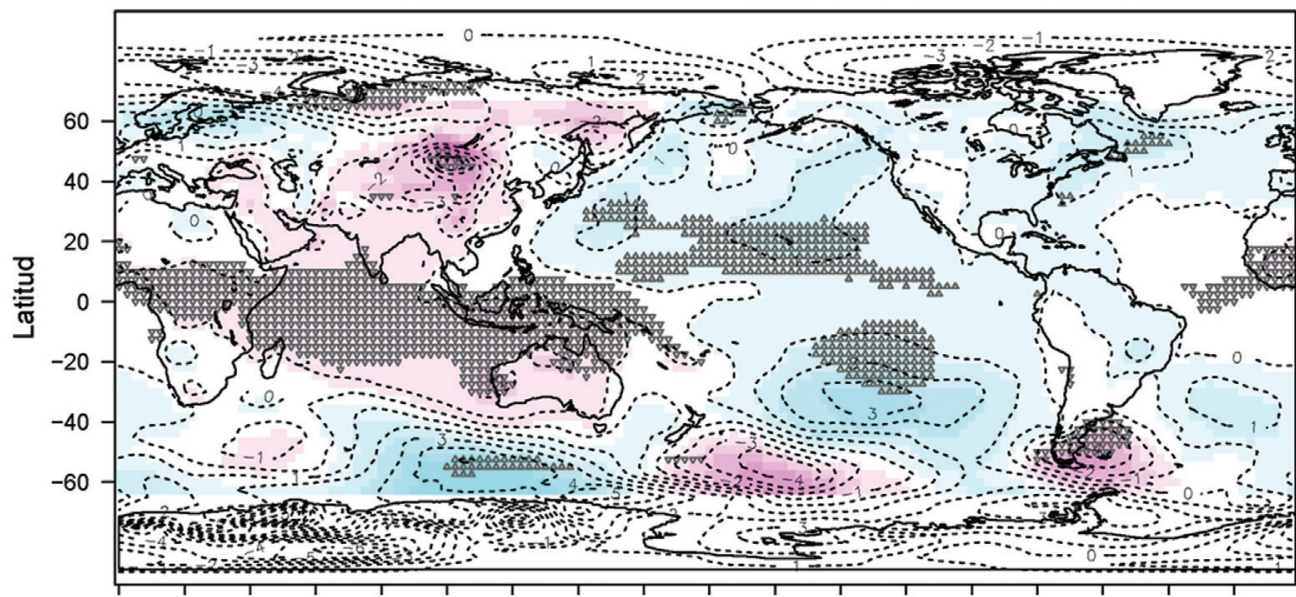

(a)
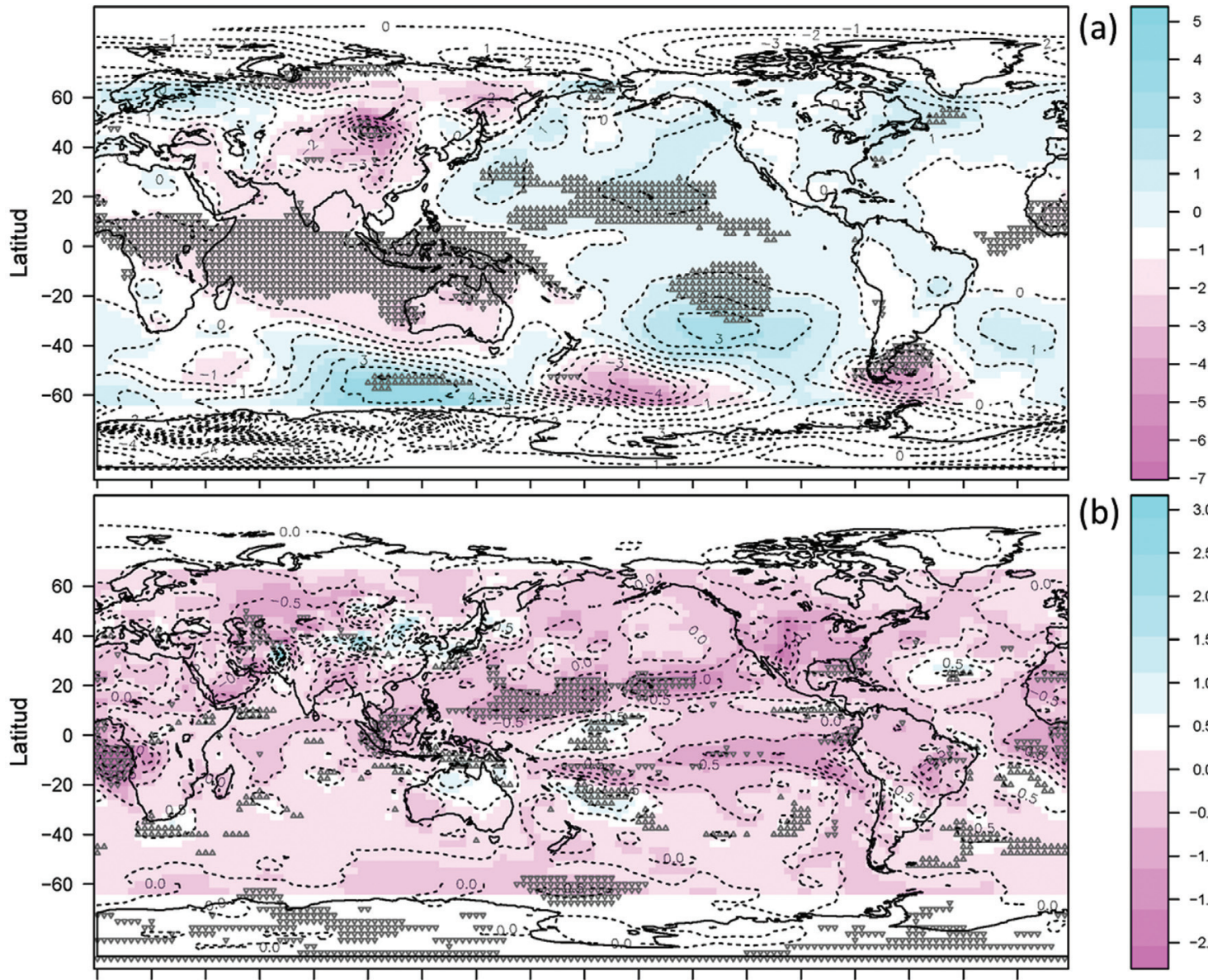

(b)
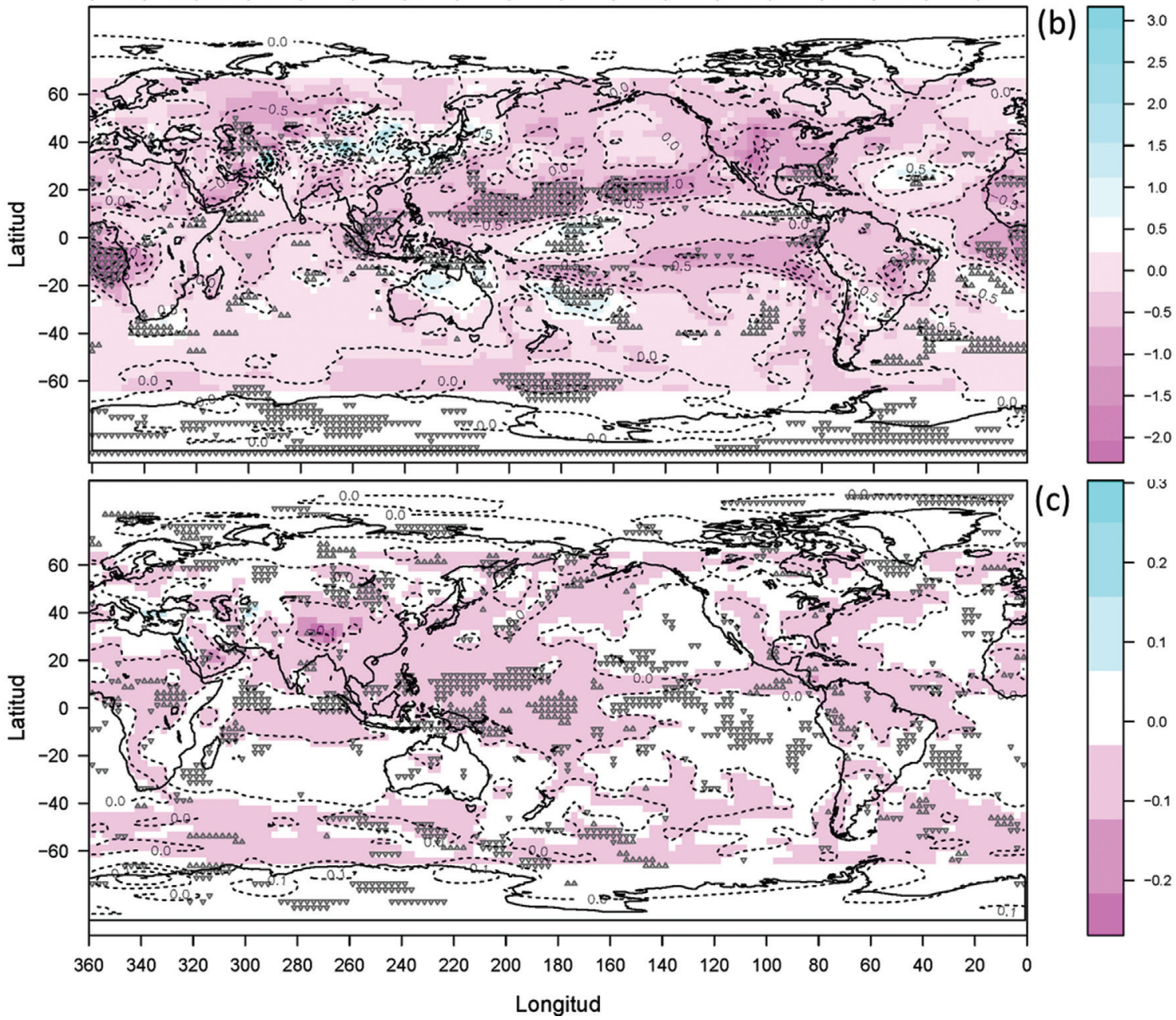

Figura 9 - Valores promedios durante la ocurrencia del evento E4 para: (a) la anomalía de la PNM en milibares, (b) la anomalía de la HE en g/kg a 700 milibares y (c) la VV en Pascal/s a 700 milibares. Los valores positivos (negativos) de VV indican un flujo descendente (ascendente). Los triángulos orientados hacia arriba (abajo) señalan que el valor medio es mayor (menor) a la media de largo plazo (1981-2010), con base en una prueba t de Student $(\alpha=0.05)$.

extiende a gran parte de la porción tropical del Océano Atlántico. Sin embargo, note que los valores de HE sobre la unidad de estudio no difieren estadísticamente de la media de largo plazo [Fig. 9(b)]. En contraste, un significativo déficit de humedad ocurre costa afuera de Ecuador (región
Niño N1+2) y el noroeste de África así como en el interior continental del NEB. Por otro lado, a este nivel de la tropósfera, la Fig. 9(c) muestra una amplia actividad convectiva sobre el norte de Sudamérica, intensificada sobre gran parte de Colombia y la vertiente Amazónica de Perú 
[Fig. 9(c)], aunque debilitada en el sureste del territorio venezolano e interior del NEB. Estos resultados parciales sugieren que el evento E4 no está relacionado con un déficit de humedad de importancia en la media tropósfera.

La intensificación de la actividad convectiva sobre Colombia parece estar vinculada al evento E4 [Fig. 9(c)]. Esta hipótesis se sustenta en los trabajos de Poveda y Mesa (1997) y Poveda et al. (2001). Dichas referencias muestran que los eventos E3, E4 y E7 coinciden con un incremento significativo en el caudal del río Cauca (Colombia) y aguas anómalamente frías en la región Niño N3.4. En contraste, los eventos E1 y E8 destacan porque tuvo lugar aportes pluviométricos deficitarios inducido por fuertes episodios El Niño. En principio, este resultado sugiere que durante la temporada de lluvia en Venezuela (junio-septiembre): los episodios secos de gran cobertura en Venezuela, los aportes pluviométricos anómalamente altos sobre gran parte del territorio colombiano y las condiciones favorables a eventos La Niña en la región Niño N3.4, podrían estar vinculados.

El campo vectorial del viento durante la ocurrencia del evento E4 en los niveles $850 \mathrm{mb}$ (altitud: $\sim 1.5 \mathrm{~km}$ ) y $200 \mathrm{mb}$ (altitud: $\sim 12 \mathrm{~km}$ ) se muestra en la Fig. 10. A $850 \mathrm{mb}$, el patrón eólico sobre el territorio venezolano no muestra un cambio significativo con relación al patrón promedio de largo plazo (1981-2010). Se destaca un debilitamiento del flujo costa afuera tanto de Ecuador como del noroeste de Perú (región Niño N1+2) e intensificación sobre el NEB. Probablemente, estas característica sea debida a una perturbación causada por la intensificación y el debilitamiento del flujo eólico vertical en dichas regiones [ver Fig. 9 (c)]. En la alta tropósfera (nivel $=200 \mathrm{Mb}$ ), se nota una intensificación del flujo eólico sobre los Llanos Centrales venezolanos (cerca de $9^{\circ} \mathrm{N}$ ), así como al norte de Brasil (cerca de $0^{\circ} \mathrm{N}$ ).

El contraste de las Figs. 8, 9 y 10 revela que los eventos E3, E4 y E7 coinciden con un enfriamiento masivo de las aguas superficiales del Océano Pacifico en las regiones Niño, en particular la región Niño N3.4, la cual es acompañada de cambios a gran escala en los patrones de presión a nivel del mar, contenido de humedad atmosférica y velocidad vertical en la media tropósfera, así como por la intensificación y el debilitamiento del flujo del aire en ciertas regiones de la baja y la alta tropósfera. En general, estas características evidencian que el mecanismo físico a gran escala que más contribuye a la presencia de los eventos E3, E4 y E7 es una modificación del patrón normal de circulación en la celda Hadley, impulsado en gran medida por un dipolo de presión a nivel del mar que se extiende sobre la porción tropical de los océanos Pacifico e Indico [Fig. 9 (a)], el cual favorece una intensificación de los vientos del este en la zona central del océano Pacifico [Fig. 10 (a)] y la presencia de aguas anómalamente frías en la región Niño N3.4 [Figs. 8 (a), 8 (b) y 8 (c)]. Adicionalmente, es probable que la intensificación de actividad con- vectiva observada sobre gran parte de Colombia durante estos eventos provoque una subsidencia compensatoria sobre el territorio venezolano (Poveda et al., 2001), inhibiendo de esta forma la generación de lluvias.

Se sabe que el dipolo del Atlántico Norte modula la variabilidad pluviométrica al noreste de Sudamérica (Riehl, 1954; Rind et al., 1986; Pulwarty et al., 1992; Venegas et al., 1997; Enfield y Alfaro, 1999; Rao et al., 2006; Kayano et al., 2013); en particular, sobre el NEB donde se le asocia a episodios secos severos (Souza et al., 2004; De Lima y Gan, 2007). Esta configuración oceánica se manifiesta como un fuerte gradiente inter-hemisférico en el Océano Atlántico dirigido hacia el sur, induciendo más lluvias de lo normal en el NEB; pues la ZCIT se desplaza más al sur de lo habitual (Hastenrath, 2000). El dipolo del Atlántico Norte está presente durante el evento E3 [ver Fig. 9(a)], pero ausente en los eventos E4 y E7; por tanto, éste no explica por sí solo, la presencia de las sequías de gran cobertura durante la temporada de lluvia venezolana.

Estudios previos han encontrado que los años severamente secos en el territorio venezolano suelen coincidir con la fase caliente del ENOS (Cárdenas et al., 2002; Martelo, 2003a; Paredes et al., 2008; Millano et al., 2009; Pérez, 2012; Peñaloza-Murillo, 2014); sin embargo, el calentamiento superficial del Océano Pacifico tropical que se distingue durante esta fase, no se observa en los eventos E3, E4 y E7 (Fig. 8).

Los resultados descritos en esta sección indican que los valores anómalamente bajos en la TSM del Océano Pacifico tropical podrían estar asociados con las sequías de gran cobertura en el territorio venezolano a lo largo de la temporada de lluvias, mientras que la TSM prevaleciente en el Océano Atlántico tendría una menor incidencia. En la próxima sección se explora en detalle la asociación entre la TSM en los océanos Pacifico y Atlántico, y la cobertura seca.

\subsection{Asociación entre los índices ONI y TNA con la cobertura seca en la unidad de estudio}

La Fig. 11 sintetiza los resultados derivados de la transformada wavelet continua, aplicada a la serie cobertura seca en la unidad de estudio (RS1). En el espectro global de potencia wavelet, la mayor parte de la potencia se concentra en las bandas: $0.97,5.20$ y 13.88 años [Fig. 11(c)]. En efecto, se distingue una señal dominante de alta frecuencia [frecuencia $=0.97$ años ( 11.3 meses $)$; potencia $=3560]$ junto a dos señales de baja frecuencia con recurrencia cercana a 5 y 14 años, respectivamente.

En el contexto temporal, las señales mencionadas son discontinuas [Fig. 11(c)]. El rango de alta frecuencia actúa durante los periodos en que RS1 presenta picos persistentes [Fig. 11(a)] (ej. 1957-64, 1971-75, 1995-98), mientras que su contraparte de baja frecuencia resulta relevante entre 1954 y 1973 (nivel $\alpha=0.05$; recurrencia próxima a 10 años). Note que los eventos E4, E7 y E8 indicados en la 


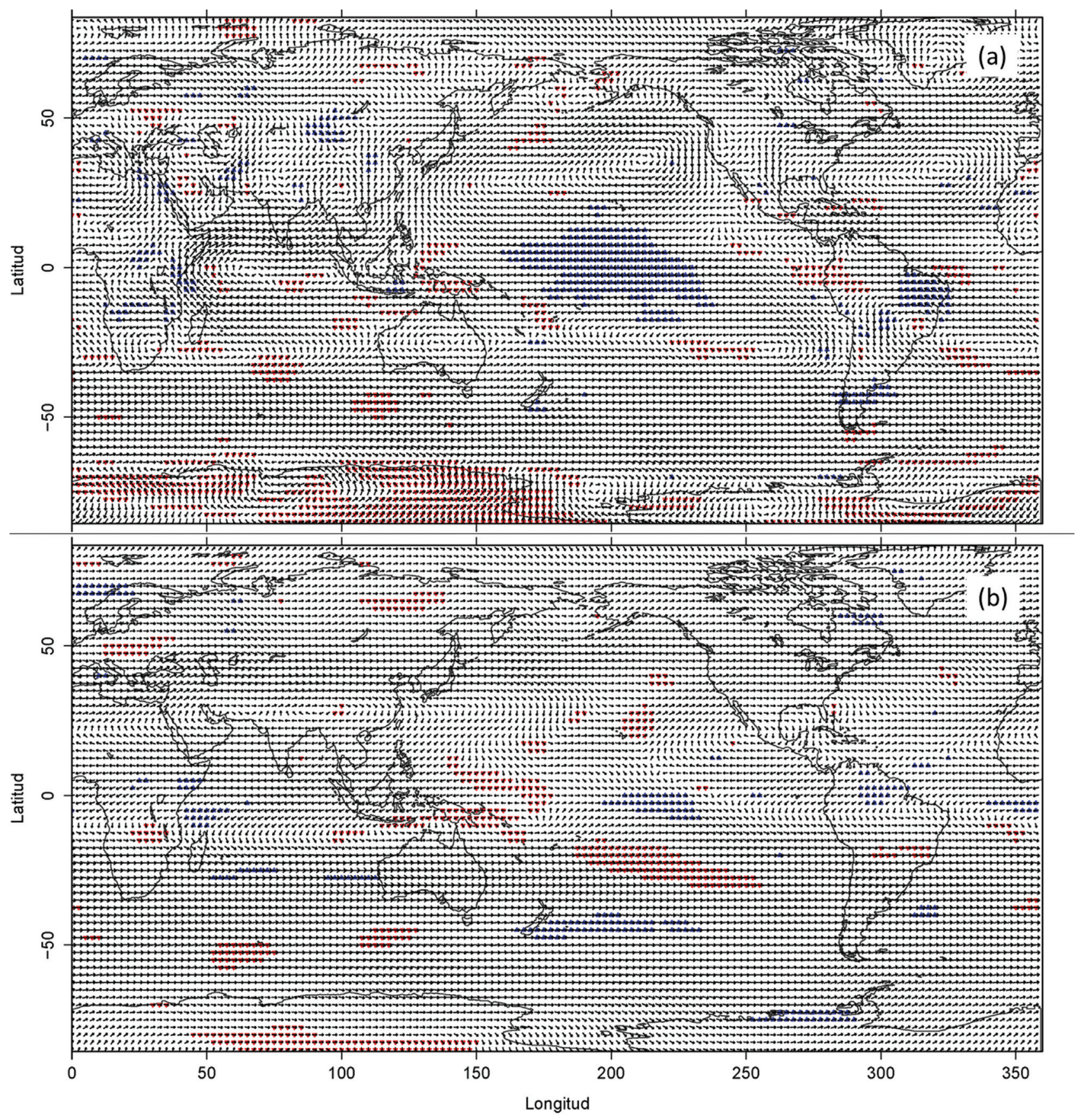

Figura 10 - Velocidad del viento promedio durante la ocurrencia del evento E4 al nivel: (a) $850 \mathrm{mb}$ y (b) $200 \mathrm{mb}$. La longitud de las flechas es proporcional a la rapidez del viento, la cual varia en: (a) desde $0.03 \mathrm{~m} / \mathrm{s} \mathrm{a} 16.62 \mathrm{~m} / \mathrm{s}$; (b) desde $0.14 \mathrm{~m} / \mathrm{s} \mathrm{a} 52.11 \mathrm{~m} / \mathrm{s}$. Los triángulos orientados hacia arriba (abajo) indican que el valor medio es mayor (menor) a la media de largo plazo (1981-2010), con base en una prueba t de Student $(\alpha=0.05)$.

Fig. 4, están incluidos en un rango de alta frecuencia (menor a 2 años); E5 y E6 no reflejan importancia en el dominio frecuencia (no significativos al nivel $\alpha=0.05$ ); mientras que E1 y E2 resultan duales, pues se asocian a las señales de alta y baja frecuencia simultáneamente (nivel $\alpha=0.05$ ). En general, la persistencia de las rachas secas en el tiempo se manifiesta por regiones con alta energía en el espectro de potencia wavelet. Esta técnica estadística no provee información sobre qué modula este fenómeno. Para investigar si estas señales son moduladas por la TSM en las porciones tropicales de los océanos Pacifico y Atlántico, se aplica un análisis de coherencia wavelet entre RS1 y ONI, y RS1 y TNA.

Los resultados derivados del análisis de coherencia wavelet entre RS1 y el índice ONI se muestran en la Fig. 12. El rango de bandas entre 2 y 8 años ( 20 a 96 meses), agrupa los valores más alto y significativos de RSQ (nivel $\alpha=0.05$ ) [Fig. 12(c)]. Este rango coincide con el periodo de 


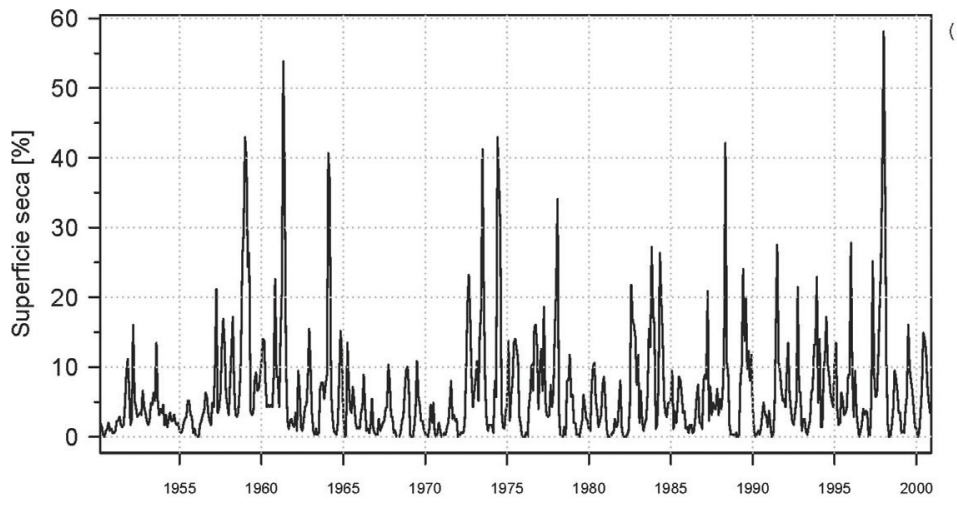

(a)
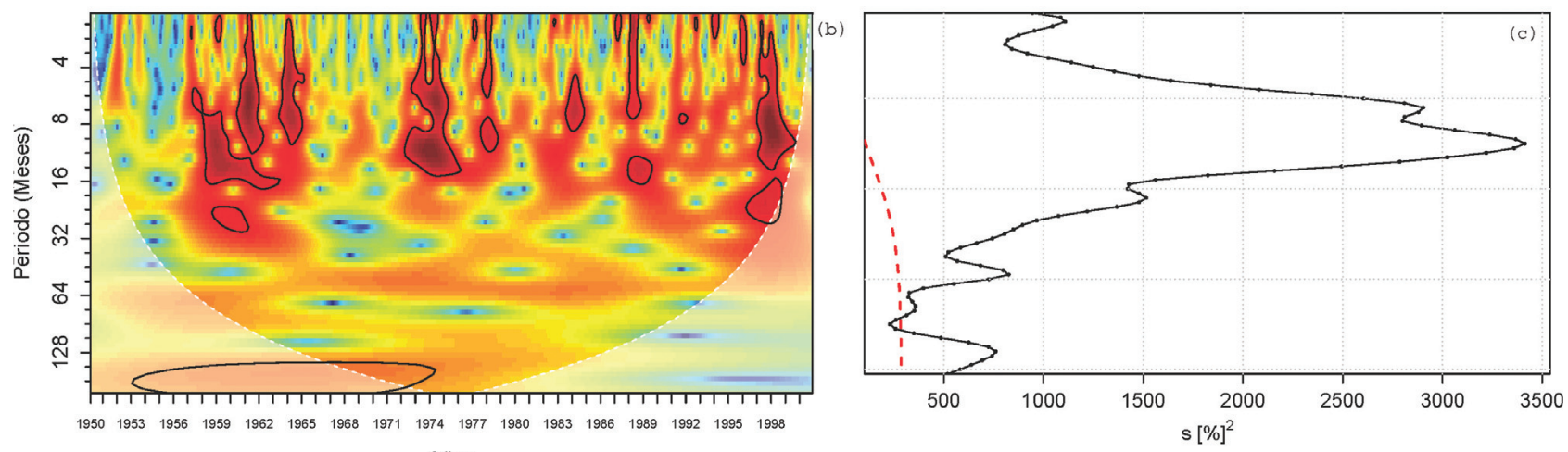

Años

Figura 11 - (a) Porcentaje de estaciones dentro de la unidad de estudio afectada por rachas secas durante el periodo 1950-2000; (b) espectro de potencia wavelet local de la variable mostrada en el panel (a) usando una ondoleta Morlet, normalizada por $1 / \mathrm{s}^{2}\left(\mathrm{~s}^{2}=61.60 \%{ }^{2}\right)$; (c) espectro de potencia global de la variable mostrada en el panel (a). Los colores graduados simbolizan la energía en el espectro de potencia (azul: baja energía; rojo: alta energía). La línea segmentada de color blanco en el panel (b) representa el cono de influencia, fuera del cual el efecto borde llega a ser importante. Las regiones encerradas por líneas gruesas en el panel (b) muestra donde la señal difiere de un proceso de ruido rojo según una prueba chi-cuadrada a un nivel de confianza del 95\%. La línea segmentada de color rojo en el panel (c) representa el valor medio de un espectro de ruido rojo con un coeficiente de retardo igual a 0.65 ,

retorno habitual del fenómeno ENOS (Torrence y Webster, 1999), evidenciando una asociación no lineal entre RS1 y la actividad del ENOS a lo largo del periodo analizado. Note en la Fig. 12(b), que el RSQ en las regiones estadísticamente significativas suele superar el valor 0.80 (regiones cerradas con color rojo); esto significa que el índice ONI en estos sub-periodos solo explica cerca del $64 \%$ de la varianza de RS1.

La comparación de las Figs 4, 12(a) y 12(b) revela que las series de tiempo RS1 y ONI están predominantemente en fase durante la evolución de los eventos E1, E2, E3, E4 y E8 (nivel $\alpha=0.05$ ). Esto implica que las variaciones de ONI y RS están sincronizadas en el tiempo, evidenciando una causalidad lineal desde ONI hacia RS para estos episodios. Sin embargo, note que durante el evento E8, el incremento progresivo de RS sucedió tres meses después de iniciarse un incremento de ONI a partir de 1989 [Fig. 12(a)]. La ocurrencia de una respuesta temporal desfasada entre ONI y la precipitación había sido advertida por Martelo (2003b) y Paredes y Guevara (2010) en el territorio venezolano.

Los eventos E5 y E6 muestran un comportamiento complejo. Por ejemplo, E5 comienza abruptamente a mediados de 1982 (Fig. 4), después de un incremento sostenido del índice ONI a partir de 1981. En este punto, E5 parece haber sido impulsado por ONI. No obstante, a pesar de que el índice ONI mantiene una tendencia positiva hasta finales de 1982, RS decrece abruptamente durante el último semestre del mismo año [Fig. 12(a)]. A mediado de 1983 se registra el evento E6, posterior a un notable pico positivo en ONI (más de $2{ }^{\circ} \mathrm{C}$ ); de hecho, las series temporales del índice ONI y RS están marcadamente desfasadas entre si [Fig. 12(a)]. El desacoplamiento de ONI y RS durante la evolución de los eventos E5 y E6 indica que los episodios El Niño de moderada intensidad, suelen desencadenar sequías de gran cobertura en el territorio venezolano, sin embargo otros mecanismos físicos no relacionados directamente con el fenómeno ENOS pueden amortiguar el impacto de las sequías inducidas por ENOS. Algunos estudios previos sugieren que la retroalimentación suelo-atmósfera durante la evolución de los episodios El Niño juega un rol importante como mecanismo modulador de la intensidad de las sequías (Poveda et al., 2001; Barbosa et al., 2006; Meng et al., 2014; Barbosa and Lakshmi Kumar, 2016); por tanto, el desfase ENOS-precipitación observado en el evento E8 así como la varianza de RS no atribuida al índice ONI, podría ser parcialmente explicada por dicha interacción. No obstante, el análisis de este aspecto esta 

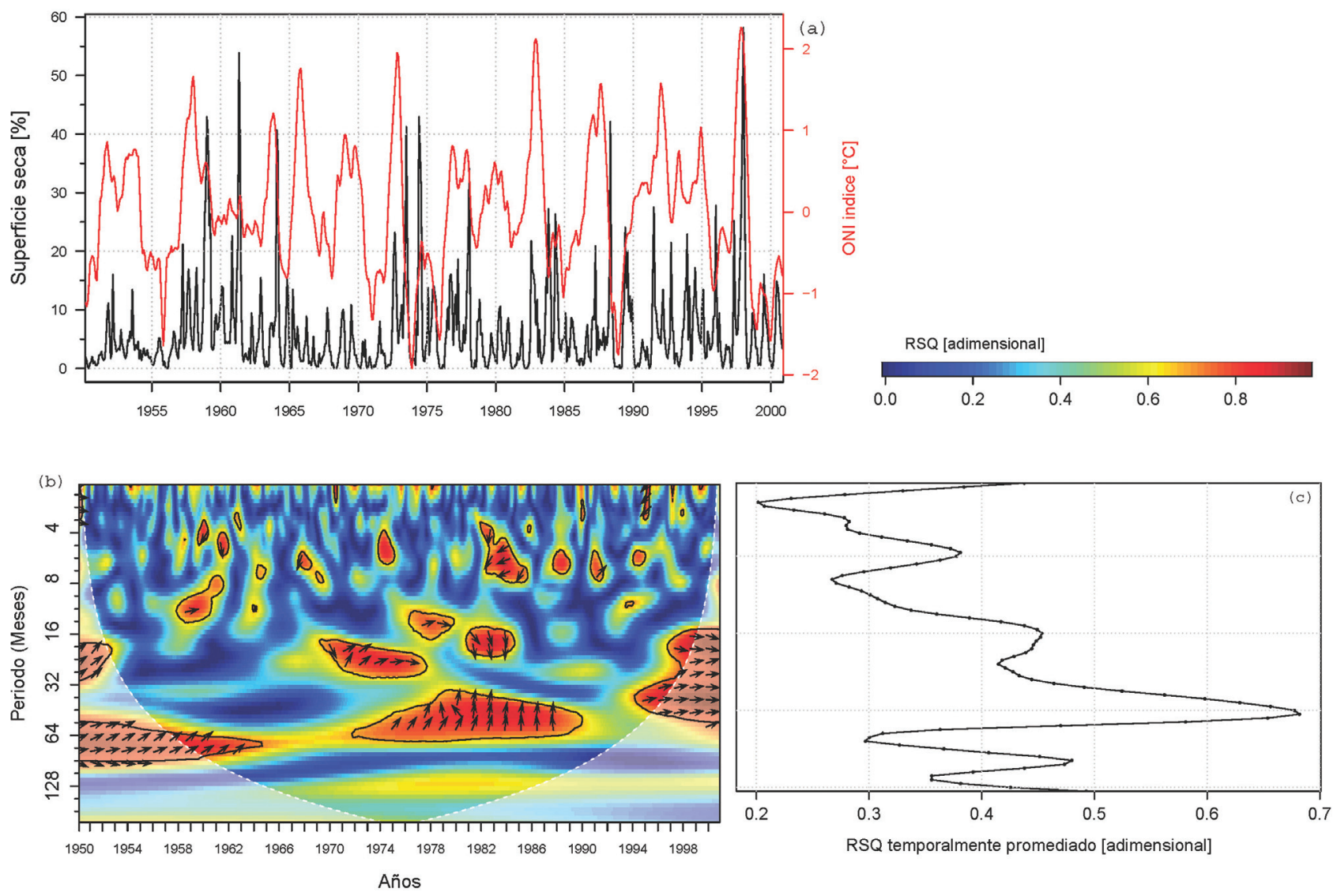

Figura 12 - (a) Porcentaje de estaciones dentro de la unidad de estudio afectada por rachas secas (línea negra) e índice ONI (línea roja) durante el periodo 1950-2000; (b) espectro de coherencia wavelet entre las variable mostradas en el panel (a) usando una ondoleta Morlet, normalizada por $1 / \mathrm{s}^{2}$ $\left(\mathrm{s}_{1}^{2}=0.62{ }^{\circ} \mathrm{C}^{2} ; \mathrm{s}_{2}^{2}=61.60 \%{ }^{2}\right)$; (c) coherencia global promediada temporalmente (RSQ) de la variable mostrada en el panel (b). Los colores graduados simbolizan la RSQ local (azul: débil; rojo: fuerte). La línea segmentada de color blanco en el panel (b) representa el cono de influencia, fuera del cual el efecto borde llega a ser importante. Las regiones encerradas en el panel (b) por líneas gruesas muestra donde la RSQ es estadísticamente significativa según una prueba chi-cuadrada a un nivel de confianza del 95\%. En el panel (b) las flechas hacia la derecha indican que las variables están en fase (relación lineal); a la izquierda, indica un desfase de $180^{\circ}$ (relación lineal desfasada); hacia arriba, la segunda señal adelanta en $90^{\circ}$ la primera señal; hacia abajo, la primera señal adelanta en $90^{\circ}$ la segunda señal.

fuera del alcance del presente estudio, por lo que debe abordarse en trabajos futuros.

La Fig. 13 ilustra las salidas del análisis de coherencia wavelet entre RS1 y el índice TNA. A diferencia del índice ONI, el índice TNA se acopla con RS1 durante cortos periodos de tiempo donde predomina una amplia gama de frecuencias menores a un año, sugiriendo que la asociación entre TNA y RS1 tiende a favorecer una escasa persistencia temporal de RS1 en el tiempo. La Fig. 13 revela varios rasgos relevantes relacionados con las sequías. Durante los eventos E1, E2 y E8: el índice TNA y RS1 están predominantemente en fase (nivel $\alpha=0.05$ ), revelando una causalidad entre la TSM en la región oceánica Atlántico Norte y la actividad de las sequías en el territorio venezolano. Una respuesta temporalmente desfasada alrededor de dos meses entre el índice TNA y RS1 resulta evidente en los eventos E3, E7 y menos obvia en el evento E4 (nivel $\alpha=0.05$ ). En estos casos, un incremento del índice TNA se observa después de haber ocurrido en RS1, indicando la inexistencia de una causalidad dirigida desde TNA hacia
RS1. Esta cualidad es generalizable a los eventos E5 y E6, donde una relación anti-fase entre el índice TNA y RS1 es notada. En conjunto, este análisis sugiere que los eventos secos de gran cobertura fuera de la temporada de lluvias son afectados por la condición térmica de las aguas superficiales prevalecientes en la región oceánica Atlántico Norte.

Los resultados previos son coherentes con la interpretación de la Fig. 8 y refuerzan la hipótesis de que la TSM en el Océano Pacifico tropical juega un rol importante sobre las sequías de gran cobertura en la unidad de estudio, mientras que la contribución de la TSM en el Océano Atlántico Norte solo resulta relevante durante los episodios secos temporalmente persistentes que evolucionan fuera de la temporada seca, en cuyo caso, ambas porciones oceánicas actúan en sinergia. Note, sin embargo, que algunas sequías de gran cobertura observadas durante la temporada de lluvia no pueden ser atribuidas a estas teleconexiones oceánicas. Los eventos E5 y E6, y en menor grado E7, no son explicados satisfactoriamente bajo este enfoque (Figs. 4, 12 y 13), debido a que las señales contrastadas 

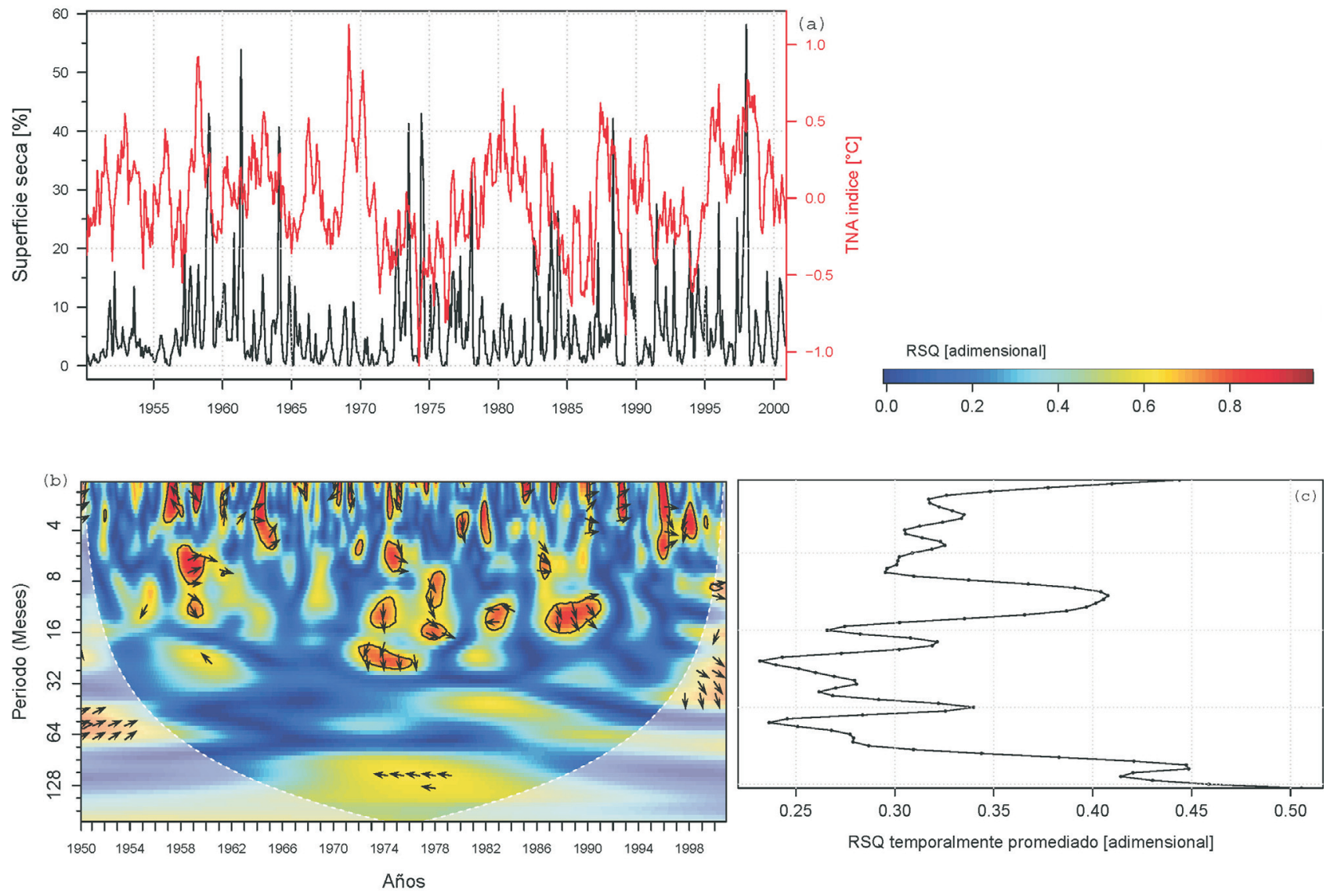

Figura 13 - Igual a la Fig. 12, pero considerando el índice TNA. $\mathrm{s}_{2}^{2}=0.11^{\circ} \mathrm{C}^{2}$.

(ONI y RS1) muestran una asociación no lineal ampliamente desfasadas. Este contexto hace suponer que el transporte deficitario de humedad a nivel de la media tropósfera [Fig. 9(b)] así como las anomalías en la circulación atmosférica de bajo y alto nivel (Fig. 10), podrían explicar parcialmente el origen de estos eventos.

Pulwarty et al. (1992) evidenciaron una relación entre la presencia de un patrón de subsidencia al sur del NEB y la ocurrencia de lluvias deficitarias en gran parte del territorio venezolano. Note en la Fig. 9c como la velocidad vertical configura un patrón dipolar entre el NEB (subsidencia debilitada) y la región amazónica de Perú (fuerte ascendencia) alineada cerca de $10^{\circ} \mathrm{S}$, la cual se refleja en la baja tropósfera por vientos intensificados sobre gran parte del NEB y vientos debilitados sobre Ecuador y el norte de Perú [Fig. 10(a)], además de un déficit de humedad sobre estas regiones [Fig. 9(b)]. Esta característica sinóptica es semejante a la descrita por Pulwarty et al. (1992), sugiriendo que podría haber favorecido la ocurrencia de E5 y E6.

Para profundizar el análisis sobre las teleconexiones oceánicas comentadas, se exploran las condiciones precedentes en las porciones tropicales de los océanos Pacifico y Atlántico durante la ocurrencia de los eventos E1 hasta E8. La Fig. 14 muestra como el evento E1 fue precedido por un persistente El Niño y aguas anómalamente cálidas en la región Atlántico Norte. Similarmente, el evento E8 coincide con un fuerte episodio El Niño y aguas cálidas en el Atlántico Norte. Las condiciones precursoras de los eventos E3, E4 y E7 son marcadamente diferentes a las observadas en los eventos E1 y E8, pues los primeros son antecedidos por eventos La Niña y aguas superficiales persistentemente frías en el Atlántico Norte.

En general, las sequías de gran cobertura que evolucionan fuera de la temporada de lluvia dominante en la unidad de estudio (junio-septiembre) son impulsadas en gran medida por intensos y/o persistentes episodios El Niño con la presencia de aguas persistentemente cálidas en el Atlántico Norte (no necesariamente anómalamente cálidas). Por otro lado, las sequías de gran cobertura dentro de la temporada húmeda están vinculadas a episodios La Niña acoplados con aguas persistentemente frías en el Atlántico Norte (no necesariamente anómalamente frías). Estas reglas no pueden generalizarse a los pulsos secos, pues la Fig. 15 sugiere que estos eventos son más frecuentes durante episodios El Niño coincidentes con aguas superficiales persistentemente frías en el Atlántico Norte.

La globalización de los resultados sustenta la hipótesis de trabajo planteada al inicio, la cual propone que gran parte de las sequías de gran cobertura en el territorio venezolano pueden ser atribuidas a fuertes acoplamientos entre 

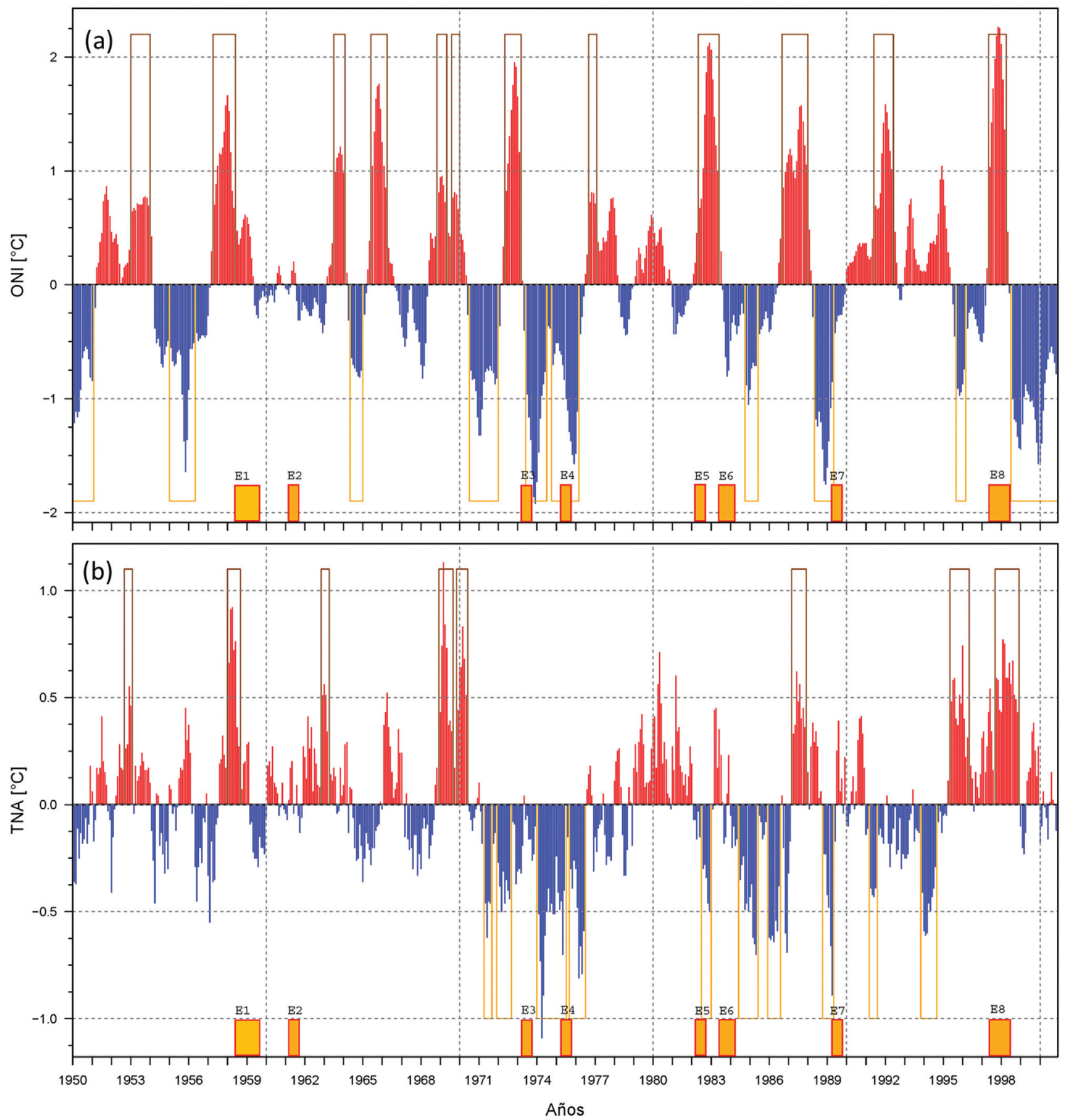

Figura 14 - Para el periodo 1950-2000: (a) índice ONI; (b) índice TNA ambos en grados Celsius. En el panel (a) los rectángulos sobre (por debajo de) $0.0^{\circ} \mathrm{C}$ indica la ocurrencia del evento (La Niña) El Niño según el criterio de Trenberth (1997). En el panel (b) los rectángulos sobre (por debajo de) $0.0^{\circ} \mathrm{C}$ indica la ocurrencia del aguas superficiales anómalamente cálidas (frías) en la región Atlántico Norte. Los rectángulos sobre el eje temporal señalan los lapsos en que sucedieron los eventos E1 hasta E8 mostrados en la Fig. 4.

ENOS y la TSM del Atlántico Norte. La ocurrencia de estos eventos a lo largo de la temporada de lluvias dominante (junio-septiembre) está asociada a la fase fría de ENOS y anomalías transitorias en la baja, media y alta tropósfera relacionadas con la circulación atmosférica (campo de vientos), la vorticidad (regiones de subsidencia y ascendencia) y el transporte de humedad a gran escala.

\section{Conclusiones}

Las características de las sequías de gran cobertura en el territorio venezolano durante el periodo 1950-2000 fueron analizadas en detalle, así como algunas variables atmosféricas y oceánicas a escala sinóptica en el lapso de tiempo en que estos eventos suceden dentro de la tempo- 


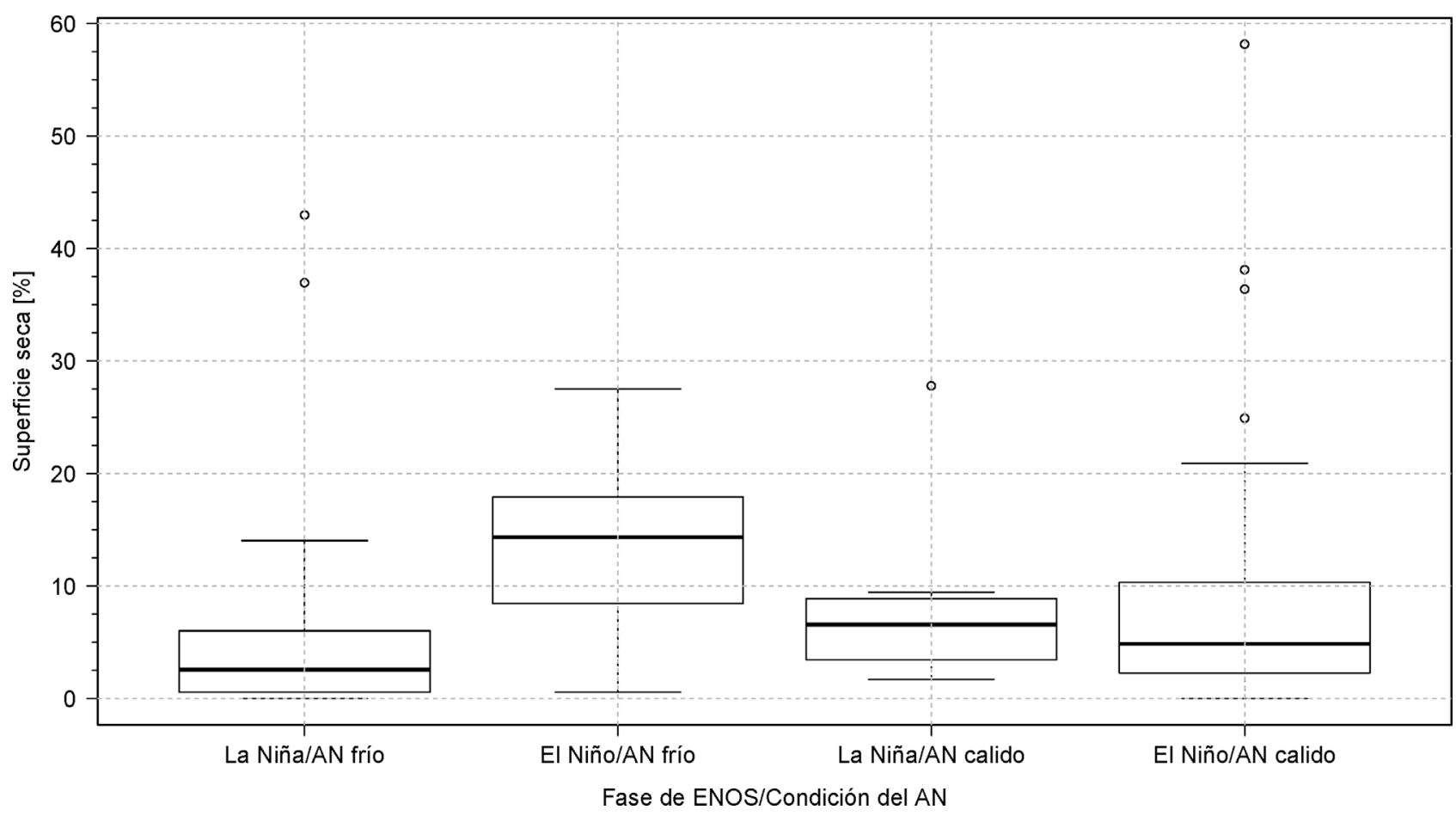

Figura 15 - Porcentaje de estaciones afectadas por rachas secas en la unidad de estudio de acuerdo a la condición prevaleciente en el Océano Pacifico tropical y la región Atlántico Norte durante el periodo 1950-2000.

rada de lluvia dominante (junio-septiembre). Se utilizó el índice de precipitación estandarizada con acumulado trimestral como índice de sequía (SPI3), y algunos productos del proyecto de re-análisis I del NCEP/NCAR y la base de datos oceánica ERSSTV3B.

Los resultados más relevantes son: i) las sequías de gran cobertura y larga duración ( $>4$ meses), ocurren fuera de la temporada de lluvia dominante. Las de menor duración (4 meses), suelen suceder a lo largo de esta temporada; ii) las sequías de gran cobertura muestran una mayor intensidad en el centro-oeste del territorio venezolano; iv) las sequías de gran cobertura que suceden en la temporada de lluvias coinciden con cambios a gran escala en los patrones de presión a nivel del mar, contenido de humedad atmosférica y velocidad vertical en la media tropósfera, y la intensificación y el debilitamiento de las corrientes de aire en ciertas regiones de la baja y la alta tropósfera. Dentro de estos cambios, destaca la intensificación de la actividad convectiva sobre Colombia; v) las sequías de gran cobertura que evolucionan fuera de la temporada de lluvia coinciden temporalmente con fuertes y/o persistentes episodios El Niño y aguas persistentemente cálidas en el Atlántico Norte; vi) las sequías de gran cobertura en la temporada húmeda suelen coincidir con episodios La Niña y aguas persistentes frías en el Atlántico Norte; vii) los pulsos secos (condiciones secas de gran cobertura y duración menor a 4 meses) son más frecuentes durante episodios El Niño y la ocurrencia de aguas persistentemente frías en el Atlántico Norte.
Se espera que estos resultandos mejoren la compresión de las sequías en Venezuela y contribuyan a reducir la vulnerabilidad y los daños causados por este fenómeno climático.

\section{Agradecimientos}

Este estudio fue financiado por las agencias FONACIT (proyecto 2011001251, Venezuela); CAPES (26001012005P5 PNPD-UFAL/Meteorología, Brasil) y CAPES/CEMADEN/MTCI (projeto Análise e Previsão dos Fenômenos Hidrometeorológicos Intensos do Leste do Nordeste Brasileiro, Brasil).

\section{Referencias}

ACEITUNO, P.; PRIETO, MA. DEL R.; SOLARI, MA. E.; MARTÍNEZ, A.; POVEDA, G.; FALVEY, M. The 18771878 El Niño episode: associated impacts in South America. Climatic Change, v. 92, n. 3-4, p. 389-416, 2009.

ADDISON, P.S. The Illustrated Wavelet Transform Handbook. CRC Press, 2002, 368 p.

AMADOR, J.A.; ALFARO, E.J.; LIZANO, O.G.; MAGAÑA, V.O. Atmospheric forcing of the eastern tropical Pacific: A review. Progress in Oceanography, v. 69, n. 2, p. 101-142, 2006.

ARGUEZ, A.; VOSE, R.S. The definition of the standard WMO climate normal: The key to deriving alternative climate normals. Bulletin of the American Meteorological Society, v. 92, n. 6, p. 699-704, 2011. 
BARBOSA, H.A.; HUETE, A.R.; BAETHGEN, W.E. A 20-year study of NDVI variability over the Northeast Region of Brazil. Journal of Arid Environments, v. 67, n. 2, p. 288307, 2006.

BARBOSA, H.A.; LAKSHMI KUMAR, T.V. Influence of rainfall variability on the vegetation dynamics over northeastern Brazil. Journal of Arid Environments, v. 124, p. 377-387, 2016.

BARNETT, T.P.; HASSELMANN, K. Techniques of linear prediction, with application to oceanic and atmospheric fields in the tropical Pacific. Reviews of Geophysics, v. 17, n. 5, p. 949-968, 1979.

BARRY, R.G.; SEIMON, A. Research for mountain area development: climatic fluctuations in the mountains of the Americas and their significance. AMBIO: A Journal of the Human Environment, v. 29, n. 7, p. 364-370, 2000.

BEHREND, H. Teleconnections of rainfall anomalies and of Southern Oscillation over the entire tropics and their seasonal dependence. Tellus A, v. 39, n. 2, p. 138-151, 1987.

BLAIN, G.; BRUNINI, O. Avaliação e adaptação do Índice de Severidade de Seca de Palmer (PDSI) e do Índice Padronizado de Precipitação (SPI) às condições climáticas do Estado de São Paulo. Bragantia, v. 64, n. 4, p. 695-705, 2005.

BLOOMFIELD, P. Fourier analysis of time series: An Introduction. John Wiley \& Sons, 2004, 288 p.

BLUNDEN, J.; ARNDT, D. State of the Climate in 2013. Bulletin of the American Meteorological Society, v. 94, n. 8, p. S1-S238, 2014.

CÁRDENAS, P.; GARCÍA, L.; GIL, A. Impacto de los eventos El Niño-Oscilación del Sur en Venezuela, Corporación Andina de Fomento, Caracas, 131 p, 2002.

CHAVES, R.; CAVALCANTI, I. Atmospheric circulation features associated with rainfall variability over southern Northeast Brazil. Monthly Weather Review, v. 129, n. 10, p. 2614-2626, 2001.

CHIANG, J.C.; VIMONT, D.J. (2004). Analogous Pacific and Atlantic Meridional Modes of Tropical Atmosphere-Ocean Variability. Journal of Climate, v. 17, n. 21, p. 4143-4158, 2004.

CLAXTON, R. The record of drought and its impact in Colonial Spanish America. In: Themes in Rural History of the Western World. Ames, Iowa, 1993, p. 194-226.

CUSHMAN, G.T. Humboldtian science, creole meteorology, and the discovery of human-caused climate change in South America. Osiris, v. 26, p. 19-44, 2011.

DE BAUTISTA, S.H.; MORALES, J.; ROMERO, E. Influencia de "El Niño" sobre el régimen pluviométrico de la cuenca del Lago de Maracaibo. Revista Técnica de Ingeniería de la Universidad del Zulia, v. 22, n. 2, p. 118-127, 1999.

DE LIMA, M.C.; GAN, M.A. Rainfall variability in the rainy season of semiarid zone of Northeast Brazil (NEB) and its relation to wind regime. International Journal of Climatology, v. 27, n. 4, p. 493-512, 2007.

DE SOUZA, E.B.; AMBRIZZI, T. ENSO impacts on the South American rainfall during 1980s: Hadley and Walker circulations. Atmósfera, v. 15, n. 2, p. 105-120, 2002.

DONG, B.; SUTTON, R.T.; SCAIFE, A.A. Multidecadal modulation of El Nino-Southern Oscillation (ENSO) variance by Atlantic Ocean sea surface temperatures. Geophysical Research Letters, v. 33, n. 8, p. L08705, 2006.
ENFIELD, D.B.; ALFARO, E.J. The dependence of Caribbean rainfall on the interaction of the tropical Atlantic and Pacific Oceans. Journal of Climate, v. 12, n. 7, p. 2093-2103, 1999.

FERNÁNDEZ, L.; FERNÁNDEZ, W. Características de la atmósfera libre sobre la región central de Venezuela. Revista de Geofísica, v. 49, p. 87-112, 1998.

FOGHIN-PILLIN, S. Tiempo y clima en Venezuela: Aproximación a una geografía climática del territorio venezolano. Venezuela, Instituto Pedagógico de Miranda José Manuel Siso Martínez, Subdirección de Investigación y Postgrado, 2002, $159 \mathrm{p}$.

GARCÍA, L.F. Situaciones meteorológicas en la región Guayana. En: Memorias de las IV Jornadas Profesionales de Edelca, GAL-4. Macagua, Edo. Bolívar, Venezuela. 1998, 10 p.

GIDDINGS, L.; SOTO, M. Teleconexiones y precipitación en América del Sur. Revista de climatología, v. 6, p. 13-20, 2006.

GONZÁLEZ, L.A.; GÓMEZ, R. High resolution speleothem paleoclimatology of northern Venezuela: a progress report. Boletín de la Sociedad Venezolana de Espeleología, v. 36, p. 27-29, 2002.

GUENNI, L.; DEGRYZE, E.; ALVARADO, K. Análisis de la tendencia y la estacionalidad de la precipitación mensual en Venezuela. Revista Colombiana de Estadística, v. 31, n. 1, p. 41-65, 2008.

GUEVARA, E.; PAREDES, F. Influencia de variables macroclimáticas sobre el régimen pluviométrico del Estado Cojedes, Venezuela. Revista Ingeniería UC, v. 14, n. 3, p. 4956, 2007.

GUEVARA, M.J. El ABC de los índices usados en la identificación y definición cuantitativa de El Niño-Oscilación del Sur (ENSO). Terra (Caracas), v. 24, n. 35, p. 85-140, 2008.

GUTIÉRREZ, E.J. Advecciones de polvo africano sobre la costa central venezolana y sus efectos sobre el desarrollo de la nubosidad. Terra XXII, v. 32, p. 13-39, 2006.

GUTIÉRREZ, E.J.; VARGA, C.I.; FERNÁNDEZ, A. Procesos sinópticos objetivos extremos de la estación lluviosa venezolana en los períodos 1956-1977 y 1978-1999. Terra Nueva Etapa, v. 24, n. 35, p. 39-61, 2011.

GUTTMAN, N. B. Comparing the Palmer drought index and the standardized precipitation index. Journal of the American Water Resources Association, v. 34, n. 1, p. 113-121, 1998.

HASTENRATH, S. Interannual and longer-term variability of upper air circulation in the northeast Brazil-tropical Atlantic sector. Journal of Geophysical Research, v. 105, n. D6, p. 7327-7335, 2000.

HEIM, R.R. A review of twentieth-century drought indices used in the United States. Bulletin of the American Meteorological Society, v. 83, n. 8, p. 1149-1165, 2002.

HU, Z. Z.; KUMAR, A.; JHA, B.; WANG, W.; HUANG, B.; HUANG, B. An analysis of warm pool and cold tongue El Ninos: Air-sea coupling processes, global influences, and recent trends. Climate dynamics, v. 38, n. 9-10, p. 20172035, 2012.

HUMBOLDT, A. VON. Temblores de tierra en Caracas. Revista del Colegio de Ingenieros de Venezuela, v. 2, n. 35, p. 157-168, 1925. 
JIMÉNEZ, G. La sequía de Caracas en el año de 1924. Revista del Colegio de Ingenieros de Venezuela, v. 2, n. 16, p. 53-58, 1924.

JOHNSON, S. El Niño, environmental crisis, and the emergence of alternatives markets in the Hispanic Caribbean, 1760s-70s. William and Mary Quarterly, v. LXII (3rd Series), n. 3, p. 365-410, 2005.

KALNAY, E.; KANAMITSU, M.; KISTLER, R.; COLLINS, W.; DEAVEN, D.; GANDIN, L.; JOSEPH, D. The NCEP/NCAR 40-year reanalysis project. Bulletin of the American Meteorological Society, v. 77, n. 3, p. 437-471, 1996.

KAYANO, M.; ANDREOLI, R.V.; FERREIRA DE SOUZA, R. Relations between ENSO and the South Atlantic SST modes and their effects on the South American rainfall. International Journal of Climatology, v. 33, n. 8, p. 2008-2023, 2013.

KAYANO, M.T.; CAPISTRANO, V.B. How the Atlantic multidecadal oscillation (AMO) modifies the ENSO influence on the South American rainfall. International Journal of Climatology, v. 34, n. 1, p. 162-178, 2014.

KNOCH, K. Die starke atmosphärische Trübung im Jahre 1926 in Venezuela. Meteorologische Zeitschrift, v. 43, p. 421, 1926.

LA CRUZ, F.; GUEVARA, E.; PAREDES, F. Caracterización de las sequías meteorológicas en los llanos de Venezuela utilizando un análisis regional de frecuencias. Revista Ingeniería UC, v. 21, n. 1, p. 70-76, 2014.

LECUNA, V. La Caracas de 1734. Boletín de la Academia Nacional de la Historia (Caracas), v. 22, n. 85, p. 34-47, 1939.

LIU, Y.; SAN LIANG, X.; WEISBERG, R. H.; Rectification of the bias in the wavelet power spectrum. Journal of Atmospheric and Oceanic Technology, v. 24, n. 12, p. 20932102, 2007.

LÓPEZ, J.; ANDRESSEN, R.; LUGO, A. Patrones de vientos troposféricos en la cuenca del Lago de Maracaibo, Venezuela. Terra. Nueva Etapa, v. 26, n. 39, p. 13-30, 2011.

LÓPEZ, N. Influencia de episodios El Niño-Oscilación del Sur (ENOS) sobre la precipitación en el Estado Monagas, Venezuela. Revista Científica UDO Agrícola, v. 12, n. 2, p. 400-406, 2012.

LOZADA, B.I.; PRELA, A. Influencia del fenómeno ENOS (El Niño y La Niña) en la disponibilidad de grados-día. Agronomía Tropical, v. 54, n. 3, p. 309-320, 2004.

LYON, B. Enhanced seasonal rainfall in Northern Venezuela and the extreme events of December 1999. Journal of Climate, v. 16, n. 13, p. 2302-2306, 2003.

MAGAÑA, V.; AMBRIZZI, T. Dynamics of subtropical vertical motions over the Americas during El Niño boreal winters. Atmósfera, v. 18, n. 4, p. 211-235, 2005.

MARTELO, M.T. Influencia de las variables macroclimáticas en el clima de Venezuela. Dirección de Hidrología, Meteorología y Oceanología, Dirección general de cuencas hidrográficas, 2003b, Ministerio del Ambiente y Recursos Naturales - Caracas: $72 \mathrm{p}$.

MARTELO, M.T. La precipitación en Venezuela y su relación con el sistema climático. Dirección de Hidrología, Meteorología y Oceanología, Dirección general de cuencas hidrográficas, 2003a, Ministerio del Ambiente y Recursos Naturales - Caracas: $72 \mathrm{p}$.
MARVEZ, P. Rasgos climáticos de los Llanos de Venezuela. Hettier y López (eds.). Tierras Llaneras de Venezuela, IRDCIDIATUNELLEZ. Editorial Venezolana. Mérida. Venezuela, 2005, p. 49-56.

MCKEE, T.B.; DOESKEN, N.J.; KLEIST, J. The relationship of drought frequency and duration to time scales. In: PROCEEDINGS OF THE 8TH CONFERENCE ON APPLIED CLIMATOLOGY, 17. Boston, MA: American Meteorological Society, 1993, p. 179-183.

MEGGERS, B.J. 1996. Possible impact of the mega-Niño events on precolumbian populations in the Caribbean area. En: PRIMER SEMINARIO DE ARQUEOLOGÍA DEL CARIBE (M. Veloz Maggiolo \& A. Caba Fuentes, edits). Museo Arqueológico Regional, Altos de Chavón, Rep. Dominicana/OEA, 1996, pp. 156-176.

MEGGERS, B.J. Archeological evidence for the impact of megaNiños events on Amazonian during the past two millennia. Climatic Change, v. 28, p. 321-338, 1994.

MENDOZA, M.; PUCHE, M. Evaluación de la ocurrencia de sequía en localidades de Venezuela. Revista de la Facultad de Agronomía LUZ, v. 24, p. 661-678, 2007.

MENG, X.H.; EVANS, J.P.; MCCABE, M.F. The impact of observed vegetation changes on land-atmosphere feedbacks during drought. Journal of Hydrometeorology, v. 15, n. 2, 759-776, 2014.

MILLANO, J.; PAREDES, F.J.; VIVAS, I. Efecto de la Oscilación Meridional (ENSO) y la temperatura superficial del océano Atlántico sobre la distribución espacio-temporal de las lluvias en el Estado Cojedes. Agrollanía Revista de Ciencia y Tecnología, v. 4, p. 103-116, 2009.

NORIA, A. Desastres en La Margarita. Epidemias y sequías durante la época colonial (1747-1751). En: III Congreso Nacional de Antropología/IV Seminario Internacional "Miguel Ángel Jusayú"/II Encuentro Nacional de Arqueólogos y Arqueólogas. Universidad del Zulia, Fac. Experimental de Ciencias, Maracaibo, 2013, p. 296.

PADILLA, M.V. El Año del Hambre - La Sequía y el Desastre de 1912 en Paraguaná. Gob. Edo. Falcón/Inst. Cultura Edo. Falcón (INCUDEF)/Fund. Lit. León Bienvenido Weffer/Grupo Tiquiba, 2012, 189 p.

PAREDES, F. J.; BARBOSA, H.; GUEVARA, E. Análisis espacial y temporal de las sequías en el nordeste de Brasil. Agriscientia, v. 32, n. 1, p. 1-14, 2015.

PAREDES, F.; GUEVARA, E. Desarrollo y evaluación de un modelo para predecir sequías meteorológicas en Los Llanos de Venezuela. Bioagro, v. 22, n. 1, p. 3-10, 2010.

PAREDES, F.; LA CRUZ, F.; GUEVARA, E. Análisis regional de frecuencia de las sequías meteorológicas en la principal región cerealera de Venezuela. Bioagro, v. 26, n. 1, p. 21$28,2014$.

PAREDES, F.; MILLANO, J.; GUEVARA, E. Análisis espacial de las sequías meteorológicas en la región de Los Llanos de Venezuela durante el período 1961-1996. Revista de Climatología, v. 8, p. 15-27, 2008.

PEÑALOZA-MURILLO, M. El Fenómeno de EL NIÑO en la Historia de Venezuela. En: Simposio Anual del Grupo Venezolano de Sociología e Historia de la Ciencia, Resumen extendido...: LXIV Convención Annual de AsoVAC, Caracas-Venezuela, 2014, p. 1/38.

PERDOMO, E. El fenómeno El Niño - Oscilación Sur y su influencia en los caudales de la cuenca del río Caroní. En: 
Memorias de las IV Jornadas Profesionales de Edelca, GAL-1. Macagua, Edo. Bolívar, Venezuela, 1998, 12 p,

PÉREZ, N. Influencia de episodios El Niño-Oscilación del Sur (ENOS) sobre la precipitación en el Estado Monagas, Venezuela. Revista Científica UDO Agrícola, v. 12, n. 2, p. 400-406, 2012.

PETERSON, L.C.; HAUG, G.H. Variability in the mean latitude of the Atlantic Intertropical Convergence Zone as recorded by riverine input of sediments to the Cariaco Basin (Venezuela). Palaeogeography, Palaeoclimatology, Palaeoecology, v. 234, n. 1, p. 97-113, 2006.

PEZZI, L.P.; CAVALCANTI, I.F. The relative importance of ENSO and tropical Atlantic sea surface temperature anomalies for seasonal precipitation over South America: a numerical study. Climate Dynamics, v. 17, n. 2-3, p. 205-212, 2001.

PIERRE, F.; TIRADO, M. Influencia del ENOS sobre la precipitación en la cuenca del río Yacambú y la depresión de Quíbor, estado Lara, Venezuela. Bioagro, v. 19, n. 1, p. 41$52,2007$.

POVEDA, G.; JARAMILLO, A.; GIL, M.M.; QUICENO, N.; MANTILLA, R.I.; Seasonality in ENSO-related precipitation, river discharges, soil moisture, and vegetation index in Colombia. Water resources research, v. 37, n. 8, p. 21692178, 2001.

POVEDA, G.; MESA, O. J. Feedbacks between hydrological processes in tropical South America and large-scale oceanatmospheric phenomena. Journal of Climate, v. 10, n. 10, p. 2690-2702, 1997.

PULWARTY, R.S.; BARRY, R.G.; RIEHL, H. Annual and Seasonal Patterns of Rainfall Variability over Venezuela. Erdkunde, v. 46, p. 273-289, 1992.

RANDEL, W.J.; WU, F.; GAFFEN, D.J. Interannual variability of the tropical tropopause derived from radiosonde data and NCEP reanalyses. Journal of Geophysical Research, v. 105(D12), p. 15509-15523, 2000.

RAO, V.B.; GIAROLLA, E.; KAYANO, M.T.; FRANCHITO, S.H. Is the recent increasing trend of rainfall over northeast Brazil related to sub-Saharan drought?. Journal of Climate, v. 19, n. 17, p. 4448-4453, 2006.

RICHMAN, M.; ANGEL, J.; GONG X. Determination of dimensionality in eingenanalysis. In: Fifth International Meeting on Statistical Climatology, Toronto, Canadá, 1992, p. 22-26.

RIEHL, H. Tropical Meteorology. McGraw-Hill, 1954, 392 p.

RIND, D.; PETEET, D.; BROECKER, W.; MCINTYRE, A.; RUDDIMAN, W. The impact of cold North Atlantic sea surface temperatures on climate: implications for the Younger Dryas cooling (11-10 k). Climate Dynamics, v. 1, n. 1, p. 3-33, 1986.

ROGERS, J.C. Precipitation variability over the Caribbean and Tropical Americas associated with the Southern Oscillation. Journal of Climate, v. 1, n. 2, p. 172-182, 1988.

RÖHL, E. Los veranos ruinosos de Venezuela. Boletín de la Academia de Ciencias Físicas, Matemáticas y Naturales (Caracas), Año XIV - Tomo XI, n. 32, p. 427-447, 1948.
ROJAS, M.; ALFARO, E. Influencia del océano Atlántico tropical sobre el comportamiento de la primera parte de la estación lluviosa en Venezuela. Tópicos Meteorológicos y Oceanográficos, v. 7, p. 88-92, 2000.

SÁNCHEZ, J. Las Sequías en Venezuela. Editorial Innovación Tecnológica/Universidad Central de Venezuela (UCV), Consejo de Desarrollo Científico y Humanístico (CDCH). Caracas, 2005, $42 \mathrm{p}$.

SMITH, T.; REYNOLDS, R.; PETERSON, T.; LAWRIMORE, J. Improvements to NOAA's Historical Merged LandOcean Surface Temperature Analysis (1880-2006). Journal of Climate, v. 21, n. 10, p 2283-2296, 2008.

SOUZA, E.D.; KAYANO, M.T.; AMBRIZZI, T. The regional precipitation over the eastern Amazon/northeast Brazil modulated by tropical Pacific and Atlantic SST anomalies on weekly timescale. Revista Brasileira de Meteorologia, v. 19, n. 2, p.113-122, 2004.

TEEGAVARAPU, R. S. Missing precipitation data estimation using optimal proximity metric-based imputation, nearestneighbour classification and cluster-based interpolation methods. Hydrological Sciences Journal, v. 59, n. 11, p. 2009-2026, 2014

TORGO, L. Data Mining with R: learning by case studies. Chapman \& Hall/CRC, 2003, 305 p.

TORREALBA, E.R.; AMADOR, J.A.; RICA, C. La corriente en chorro de bajo nivel sobre los Llanos Venezolanos de Sur América. Revista de Climatología, v. 10, p. 1-20, 2010.

TORRENCE, CH.; COMPO, G.; A Practical Guide to Wavelet Analysis. Bulletin of the American Meteorological Society, v. 79, n. 1, p. 61-78, 1998.

TORRENCE, CH.; WEBSTER, P.; Interdecadal Changes in the ENSO-Monsoon System. Journal of Climate, v. 12, n. 8, p. 2679-2690, 1999.

TRENBERTH, K.E. The definition of El Niño. Bulletin of the American Meteorological Society, v. 78, n. 12, p. 27712777, 1997.

VASEGHI, S.V. Advanced Digital Signal Processing and Noise Reduction: Fourth edition. John Wiley and Sons, 2000, 544 p.

VENEGAS, S.A.; MYSAK, L.A.; STRAUB, D.N. Atmosphereocean coupled variability in the South Atlantic. Journal of Climate, v. 10, n. 11, p. 2904-2920, 1997.

VILA, M.A. Las Sequías en Venezuela. Fondo Editorial Común, S.C. Caracas, 1975, $176 \mathrm{p}$.

WALSH, R.P.; LAWLER, D.M. Rainfall seasonality: description, spatial patterns and change through time. Weather, v. 36, p. 201-208, 1981.

WILKS, D.S. Statistical methods in the atmospheric sciences, Academic press, 2011, v. 100.676 p.

WILLIAMS, E.; DALL'ANTONIA, A.; DALL'ANTONIA, V.; ALMEIDA, J.M.; SUAREZ, F.; LIEBMANN, B.; MALHADO, A.C. The drought of the century in the Amazon Basin: An analysis of the regional variation of rainfall in South America in 1926. Acta Amazonica, v. 35, n. 2, p. 231-238, 2005.

All the contents of this journal, except where otherwise noted, is licensed under a Creative Commons Attribution License CC-BY. 